\title{
The Contrasting Dynamics of the Buoyancy-Forced Lofoten and Greenland Basins
}

\author{
S. L. YPMA ${ }^{\mathrm{a}}$ \\ Delft University of Technology, Delft, Netherlands \\ M. A. SPALL \\ Woods Hole Oceanographic Institution, Woods Hole, Massachusetts \\ E. LAMBERT \\ Institute for Marine and Atmospheric Research Utrecht, Utrecht University, Utrecht, Netherlands \\ S. Georgiou, J. D. Pietrzak, And C. A. Katsman \\ Delft University of Technology, Delft, Netherlands
}

(Manuscript received 15 November 2019, in final form 28 January 2020)

\begin{abstract}
The Nordic seas are commonly described as a single basin to investigate their dynamics and sensitivity to environmental changes when using a theoretical framework. Here, we introduce a conceptual model for a two-basin marginal sea that better represents the Nordic seas geometry. In our conceptual model, the marginal sea is characterized by both a cyclonic boundary current and a front current as a result of different hydrographic properties east and west of the midocean ridge. The theory is compared to idealized model simulations and shows good agreement over a wide range of parameter settings, indicating that the physics in the two-basin marginal sea is well captured by the conceptual model. The balances between the atmospheric buoyancy forcing and the lateral eddy heat fluxes from the boundary current and the front current differ between the Lofoten and the Greenland Basins, since the Lofoten Basin is more strongly eddy dominated. Results show that this asymmetric sensitivity leads to opposing responses depending on the strength of the atmospheric buoyancy forcing. Additionally, the front current plays an essential role for the heat and volume budget of the two basins, by providing an additional pathway for heat toward the interior of both basins via lateral eddy heat fluxes. The variability of the temperature difference between east and west influences the strength of the different flow branches through the marginal sea and provides a dynamical explanation for the observed correlation between the front current and the slope current of the Norwegian Atlantic Current in the Nordic seas.
\end{abstract}

\section{Introduction}

The Nordic seas form an important gateway between the Atlantic Ocean and the Arctic Ocean. Warm and saline waters enter the Nordic seas from the south and facilitate a rich ecosystem and a mild climate in Norway (e.g., Rhines et al. 2008; Mork and Skagseth 2010). The western side of the Nordic seas is filled with fresh and cold waters originating from the Arctic. Mixing of water masses from these different sources in addition to severe

\footnotetext{
${ }^{a}$ Current affiliation: Institute for Marine and Atmospheric Research Utrecht, Utrecht University, Utrecht, Netherlands.
}

Corresponding author: Stefanie Ypma, s.l.ypma@uu.nl winter conditions make the Nordic seas a crucial region for dense water mass formation (e.g., Eldevik et al. 2005; Messias et al. 2008; Våge et al. 2015). The dense waters flow across the Greenland-Scotland Ridge into the Atlantic via the overflows and contribute to the lower limb of the Atlantic meridional overturning circulation (AMOC; Dickson and Brown 1994; Hansen and Østerhus 2000). Therefore, changes in the properties and dynamics of the Nordic seas impact not only the local climate and ecosystem, but also the global climate through changes in the ocean circulation.

Global mean atmospheric temperatures are expected to increase by $3.7^{\circ} \mathrm{C}$ under the RCP 8.5 (high emission) scenario by the end of the century (IPCC 2013). Due to Arctic amplification, the expected warming above the 

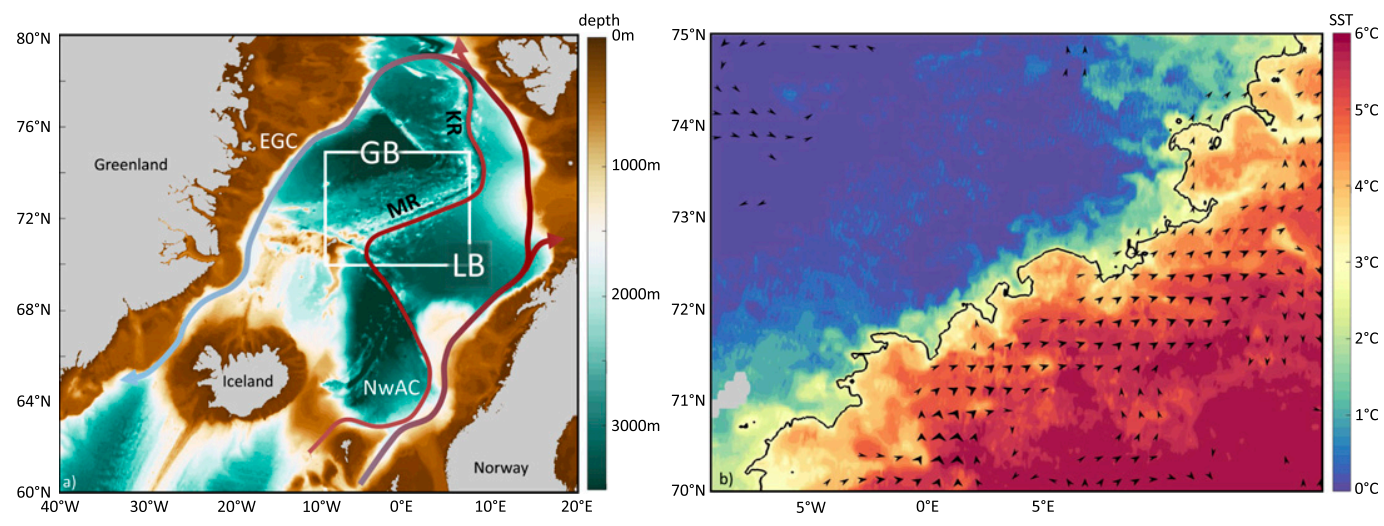

FIG. 1. (a) Schematic of the circulation in the Nordic seas and bathymetry. (b) Sea surface temperature (SST) from AVHHR sensor: image of 29 Apr 2017, showing the temperature of the Lofoten Basin and the Greenland Sea at the location of the white box indicated in (a) (the black line is the $3^{\circ} \mathrm{C}$ contour). The black arrowheads show the 2017 mean geostrophic velocity from AVISO satellite altimetry for velocities stronger than $0.04 \mathrm{~m} \mathrm{~s}^{-1}$. NwAC: Norwegian Atlantic Current, EGC: East Greenland Current, LB: Lofoten Basin, GB: Greenland Basin, MR: Mohn Ridge, and KR: Knipovich Ridge.

Nordic seas will exceed that of the midlatitudes by at least a factor of 2 (e.g., Screen and Simmonds 2010). The warming is expected to enhance the positive trend of the North Atlantic Oscillation (NAO) observed since the 1960s (e.g., Hurrell et al. 2001). A positive NAO phase often coincides with reduced heat loss from the Nordic seas to the atmosphere and increased precipitation and river runoff (Furevik and Nilsen 2005). Both mechanisms tend to reduce convection events by stabilizing the water column. However, in recent years, mixed layer depths in the Greenland Basin have deepened, possibly associated with increased near-surface salinities (Brakstad et al. 2019). Due to the rather complex nature of the Nordic seas it is therefore difficult to predict how it will respond to climate change and which physical mechanisms drive its response.

Paleo records show that the Nordic seas have undergone large changes in both hydrography and dynamics in the past (e.g., Fronval and Jansen 1996; Andersen et al. 2004). However, the spatial and temporal resolutions of these records are low and the underlying mechanisms of the observed changes are not clear. Unfortunately, fully coupled climate models lack the resolution to properly resolve the dynamical processes that play a role in the Nordic seas (e.g., Tréguier et al. 2005; Danabasoglu et al. 2014; Langehaug et al. 2017). An alternative way to shed light on what actually controls dynamical changes in marginal seas like the Nordic seas is to use an idealized approach.

Conceptual models described by, for example, Spall (2004), Walin et al. (2004), Straneo (2006), and Iovino et al. (2008) have been applied to generic marginal seas subject to buoyancy loss. These studies characterize the marginal sea by a motionless interior and a single buoyant boundary current. They have proven to give reasonable predictions for water mass properties in marginal seas like the Labrador Sea. Furthermore, the analytical frameworks developed in these studies have increased the understanding of the role of eddies and topography on the dynamics in these regions and they provide means to interpret projections from climate models and observed changes in the past. The comparison between results from the conceptual models with high-resolution (idealized) model simulations is surprisingly good, considering the number of simplifications made to enable analytical solutions.

The theories developed in Straneo (2006) and Spall (2004) were motivated by the properties of convection in the Labrador Sea, whereas the studies by Iovino et al. (2008) and Spall (2011) focused on the Nordic seas by adding the dynamical role of the Greenland-Scotland Ridge. The latter studies still describe the Nordic seas by one interior basin and a single boundary current. However, observations show that the eastern side of the Nordic seas (the Lofoten Basin) differs from the western side (the Greenland Basin) regarding hydrography and dynamics (see Fig. 1).

A warm and saline water mass fills the upper $500 \mathrm{~m}$ of the Lofoten Basin, whereas the Greenland Basin is filled with fresh and cold waters (Fig. 1b; e.g., Blindheim and Østerhus 2005; Nilsen and Falck 2006; Latarius and Quadfasel 2016). A conceptual model using a single interior basin is not able to capture this large difference in hydrography, making a two-basin approach more suitable. The difference in water masses between east and west creates a strong front aligned with the MohnKnipovich Ridge (Bosse and Fer (2019), see satellite image in Fig. 1b). As a consequence, the Atlantic Water that flows through the Nordic seas takes different paths; 
one along the slope of the Norwegian continental margin [the inner branch of the Norwegian Atlantic Current (NwAC)] and one along the front (the outer branch of the NwAC, Fig. 1a; e.g., Voet et al. 2010). Observations indicate an anticorrelation between the strength of the front current and the slope current on seasonal and decadal time scales (Mork and Blindheim 2000; Bosse and Fer 2019; Broomé et al. 2019; Raj et al. 2019), implying that these currents are dynamically connected. For the description of a marginal sea like the Nordic seas, one therefore needs to consider not only a boundary current, but also a front current.

Previous studies have shown that the midocean ridge is essential in separating the east from the west (e.g., Rossby et al. 2009; Spall 2010). Another important topographic feature in the Nordic seas is the steepening of the coastal slope near the Lofoten Islands. Due to the increased instability of the inner branch of the NwAC near this topographic steepening, anticyclonic eddies continuously replenish the interior of the Lofoten Basin with warm and saline waters from the boundary current (e.g., Volkov et al. 2013; Isachsen 2015; Richards and Straneo 2015). Due to the wide horizontal extent of this warm water mass, the buoyancy loss over the Lofoten Basin is much larger than over the Greenland Basin (Segtnan et al. 2011). So, the Lofoten Basin differs from the Greenland Basin also from a dynamical point of view. Observations corroborate the view that the eastern and western basin are dynamically different as the basins do not change their properties uniformly over time (e.g., Fronval and Jansen 1996; Andersen et al. 2004; Furevik and Nilsen 2005).

The main aim of our study is to investigate the response of the Nordic seas to a changing atmospheric temperature and to provide a physical understanding of the mechanisms involved. A conceptual model is proposed by extending the theoretical framework described in Spall (2011) to a two-basin marginal sea with both a slope current and a front current. The model is tested against numerical simulations for a wide range of parameters. Using this conceptual model, we address the following questions:

1) How can the dynamics of a two-basin marginal sea be described by a conceptual model?

2) What controls the mean hydrography and volume transport in a two-basin marginal sea?

3) How does the addition of a ridge change the marginal sea response to changes in atmospheric buoyancy forcing?

Section 2 describes the numerical simulation and summarizes the conceptual model from Spall (2011) that is used as a base for our study. Section 3 provides the extended analytical framework describing a two-basin marginal sea and discusses the implications of this extension. In section 4, the sensitivity of the marginal sea to changes in atmospheric buoyancy forcing is investigated using both the conceptual model and the numerical simulations and a discussion on the results and conclusions are provided in section 5 .

\section{Methods}

To test the validity of the conceptual model described in section 3, estimates from the analytical framework are compared to diagnostics from an eddy-resolving regional ocean circulation model. A short description of the numerical simulations is given in section $2 \mathrm{a}$, including details on the model configuration [section $2 \mathrm{a}(1)$ ] and a description of the reference simulation [section $2 \mathrm{a}(2)$ ]. The idealized approach to the model setup allows for straightforward comparison between the output and the estimates from the theoretical framework [section $2 \mathrm{a}(3)$ ]. For the conceptual model, we build upon the one-basin framework derived by Spall (2011) and use a similar approach but applied to a two-basin marginal sea rather than a single basin. For reference, the main derivation and assumptions of Spall (2011) are summarized in section $2 b$.

\section{a. Idealized numerical model simulation of the Nordic seas}

An idealized configuration of the Massachusetts Institute of Technology (MIT) general circulation model is used in this study (Marshall et al. 1997). The aim of the simulations is to capture the two-basin character of the Nordic seas; an eddy-rich and warm basin in the east, a cold basin in the west, a strong front between the eastern and western basin aligned with a midocean ridge, and the branching of the inflow from the south.

\section{1) Model CONFiguration}

The model domain consists of a $1000 \times 1400 \mathrm{~km}^{2}$ basin (the bathymetry is shown in Fig. 2a). The horizontal grid spacing is $5 \mathrm{~km}$, and the model has 33 levels in the vertical with thickness ranging from $20 \mathrm{~m}$ in the upper layers to $200 \mathrm{~m}$ near the bottom. At $y=500 \mathrm{~km}$ an island is located (representing Iceland), separating the north (the Nordic seas) from the south (the North Atlantic Ocean). At this latitude the in- and outflow is partly obstructed by a sill of $1000-\mathrm{m}$ depth (representing the Greenland-Scotland Ridge). A midocean ridge of 1200-m depth separates the eastern (Lofoten) basin from the western (Greenland) basin (representing the Mohn-Knipovich Ridge). The slopes of the midocean ridge, the island and the perimeter of the basin are linear 
temperature $\left({ }^{\circ} \mathrm{C}\right)$
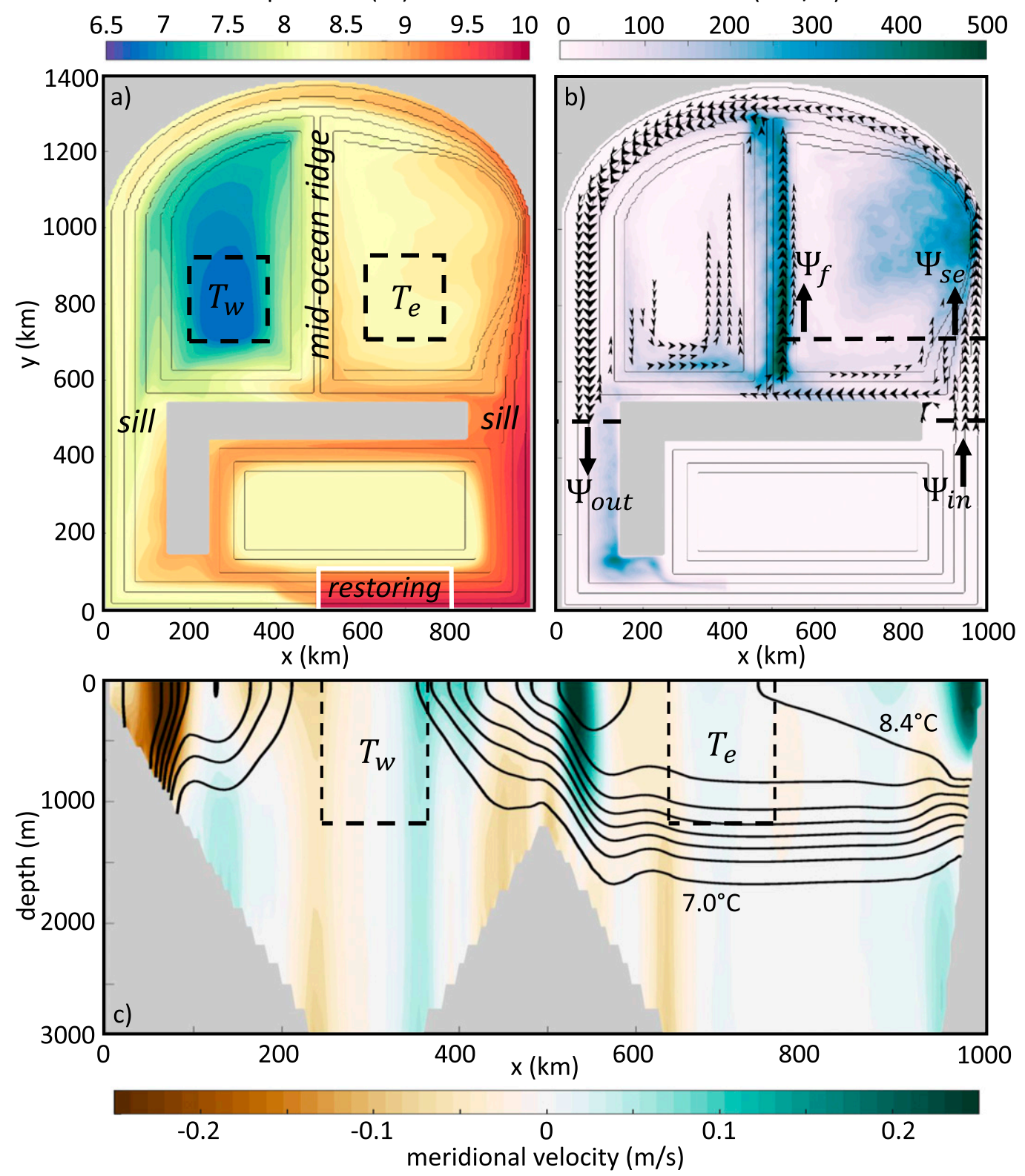

FIG. 2. (a) Five-year mean sea surface temperature (color) and bathymetry (black contours) of the reference simulation. The black boxes indicate regions over which the mean interior eastern basin temperature $T_{e}$ and western basin temperature $T_{w}$ are calculated. (b) Five-year mean surface eddy kinetic energy (shading) and surface velocity $\geq 0.05 \mathrm{~m} \mathrm{~s}^{-1}$ north of the sill (black arrowheads). The horizontal dashed lines indicate where the transport of the inflow $\Psi_{\text {in }}$, the outflow $\Psi_{\text {out }}$, the slope current along the eastern basin $\Psi_{\text {se }}$, and the front current $\Psi_{f}$ are evaluated. (c) Cross section at $y=750 \mathrm{~km}$ of the 5 -yr mean meridional velocity (shading) and mean temperature (contours; contour interval $0.2^{\circ} \mathrm{C}$ ).

with a factor of 0.012 . In the east, the topographic slope varies from 0.012 to 0.062 to resemble the region of steep topography near the Lofoten Islands (see contours in Figs. 2a,b).

A buoyant cyclonic boundary current is forced along the perimeter of the model domain by restoring temperature and velocity in a region south of the island (white box in Fig. 2a). A short restoring time scale of $2 \mathrm{~h}$ is used. In the restoring region, temperature is restored to $10^{\circ} \mathrm{C}$ at the surface, and to constant vertical and meridional buoyancy gradients of $N_{0}^{2}=4 \times 10^{-6} \mathrm{~s}^{-2}$ and $M_{0}^{2}=1.6 \times 10^{-8} \mathrm{~s}^{-2}$, respectively. Using thermal wind balance and assuming 
zero flow at the bottom, these values result in a restoring target of the zonal velocity of $0.4 \mathrm{~m} \mathrm{~s}^{-1}$ at the surface, reducing linearly to the bottom. This yields a first baroclinic deformation radius of $\sim 10 \mathrm{~km}$. The velocity is restored in order to limit the spinup time of the simulation.

The transport across the sill is variable and depends on the surface forcing applied north of the sill. There, the ocean is cooled by restoring the surface temperature toward a prescribed atmospheric temperature $T_{A}$, where the resulting heat flux is given by

$$
Q=\int_{S}\left(T-T_{A}\right) \Gamma d A
$$

Here, $\Gamma$ is the restoring strength $\left(\mathrm{W} \mathrm{m}^{-2} \mathrm{~K}^{-1}\right)$. Note that the heat flux $Q$ is positive when the ocean is losing heat to the atmosphere. The simulations are run for 60 years after which equilibrium is reached. Means over the final 5 years of the simulation are used for the analyses presented in this paper. Further details on the model configuration can be found in Spall (2011), who uses a similar configuration without the midocean ridge.

\section{2) HYDROGRAPHIC AND DYNAMICAL} PROPERTIES OF THE REFERENCE SIMULATION

The parameters for the reference simulation are chosen such to show the closest resemblance to reality. To match the observed heat loss over the Lofoten Basin and the Greenland Basin, $\Gamma=16 \mathrm{~W} \mathrm{~m}^{-2} \mathrm{~K}^{-1}$ and $T_{A}=$ $4^{\circ} \mathrm{C}$ are used. These yield a surface heat loss of $46 \mathrm{~W} \mathrm{~m}^{-2}$ over the western basin and $70 \mathrm{~W} \mathrm{~m}^{-2}$ over the eastern basin (NCEP-2 estimates give respectively 43 and $67 \mathrm{Wm}^{-2}$ for the Greenland and the Lofoten Basin; see Segtnan et al. 2011). Note that, just as in observations (Isachsen et al. 2007), the net buoyancy loss to the atmosphere over the Lofoten Basin is much larger than over the Greenland Basin. In the numerical simulations the atmospheric temperature $T_{A}$ is uniform. Therefore, the temperatures of the eastern and western basin differ due to internal ocean dynamics, not due to a spatial difference in atmospheric buoyancy forcing (in the remainder of the paper "forcing" always relates to buoyancy forcing).

In the reference simulation, the surface temperature (SST) of the eastern basin is on average $1.4^{\circ} \mathrm{C}$ higher than the western basin (Figs. 2a,c). Recall that in the numerical model, density depends on temperature only. In observations, the temperature difference between the Lofoten and the Greenland Basins is much larger $\left[\Delta T=\sim 6^{\circ} \mathrm{C}\right.$; see Bosse and Fer (2019) and Fig. 1], but the density difference is for a large part compensated by salinity $\left(\Delta \rho=\sim 0.30 \mathrm{~kg} \mathrm{~m}^{-3}\right.$; see Piechura and
Walczowski 1995; Bosse and Fer 2019). Therefore, the density difference, which governs the dynamics along the front, is similar in the reference simulation $(\Delta \rho=$ $\sim 0.28 \mathrm{~kg} \mathrm{~m}^{-3}$ ) compared to the observations.

The inflow east of the island separates into a current along the eastern boundary (hereinafter the slope current) and a current along the midocean ridge (hereinafter the front current, see arrows in Fig. 2b). The structure of both branches is clearly visible in the cross section in Fig. 2c (green shading at $x=550 \mathrm{~km}$ and $x=$ $950 \mathrm{~km}$ ). The slope and front current represent the inner and outer branches of the NwAC and display a gradual cooling in the downstream direction (Fig. 2a). Both currents are unstable; the eddy kinetic energy (EKE) shown in Fig. 2 b reveals enhanced eddy activity along the midocean ridge and near the region where the topography is steep. This region of steep topography leads to increased instability of the boundary current resulting in warm-core eddy shedding as observed near the Lofoten Islands (e.g., Poulain et al. 1996; Spall 2010; Isachsen et al. 2012). It is this enhanced lateral eddy heat flux in the east that leads to a warmer Lofoten Basin than Greenland Basin, and therefore a larger surface heat loss in the east than in the west (see also Spall 2010).

\section{3) DEFINITION OF PARAMETERS USED FOR COMPARISON WITH CONCEPTUAL MODEL}

The idealized model simulations serve as a tool to test the conceptual model described in section 3 for a wide range of parameter settings. To enable comparison between the numerical simulations and the solutions from the conceptual framework, different quantities need to be derived. The conceptual model described in section 3 provides estimates for the interior basin temperature in the east $T_{e}$ and in the west $T_{w}$, for the temperature of the outflowing water mass $T_{\text {out }}$ and for the volume transport of the inflow $\Psi_{\text {in }}$, the slope current $\Psi_{\text {se }}$, and the front current $\Psi_{f}$.

The interior basin temperature is calculated by taking the depth average of the regions indicated by the boxes in Fig. 2a. The temperature of the inflowing and outflowing water mass is determined by taking the transport-weighted mean of the in- and outflow at the sill (horizontal lines in Fig. $2 \mathrm{~b}$ at $y=500 \mathrm{~km}$ ). The transport of the slope current along the eastern boundary $\Psi_{\text {se }}$ and the front current $\Psi_{f}$ are calculated at $y=700 \mathrm{~km}$ (horizontal dashed line Fig. 2b). The transport of the slope current $\Psi_{\text {se }}$ is given by the northward flow east of $x=950 \mathrm{~km}$ in the upper $1000 \mathrm{~m}$ (see Fig. 2c). The front current is meandering and consists of a northward and southward flowing part that is not always clearly distinguishable. Therefore, the transport of the front current $\Psi_{f}$ is 


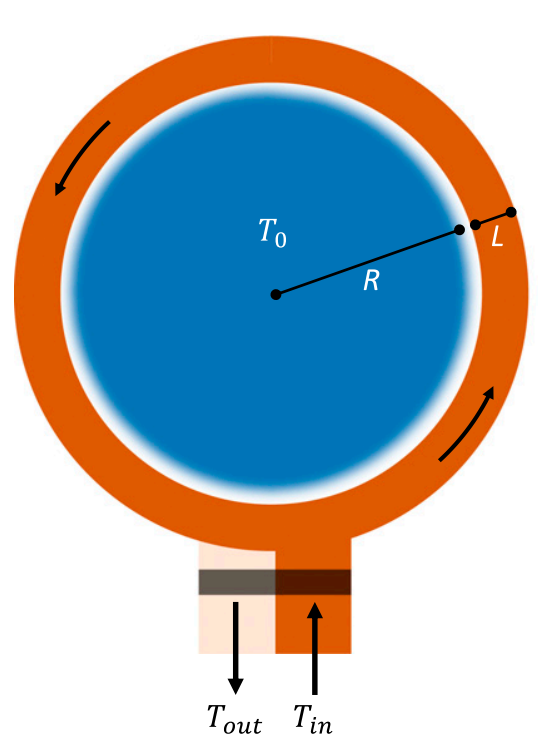

a) 1 basin

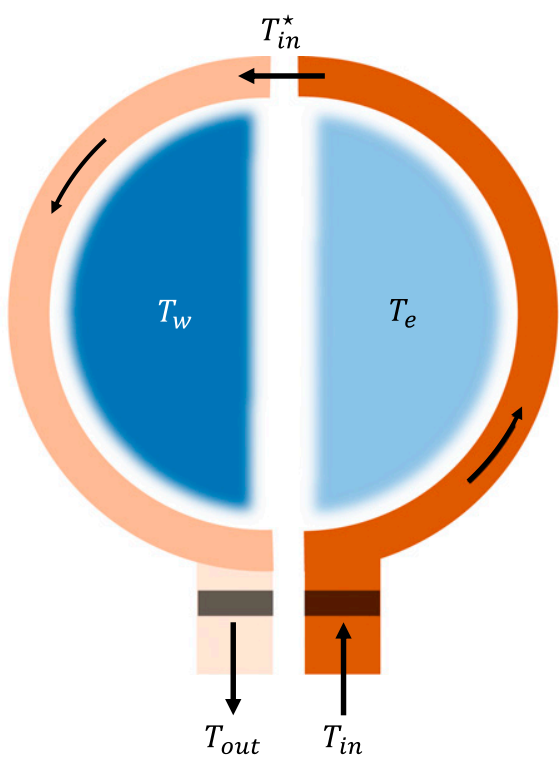

b) 2 basin_simple

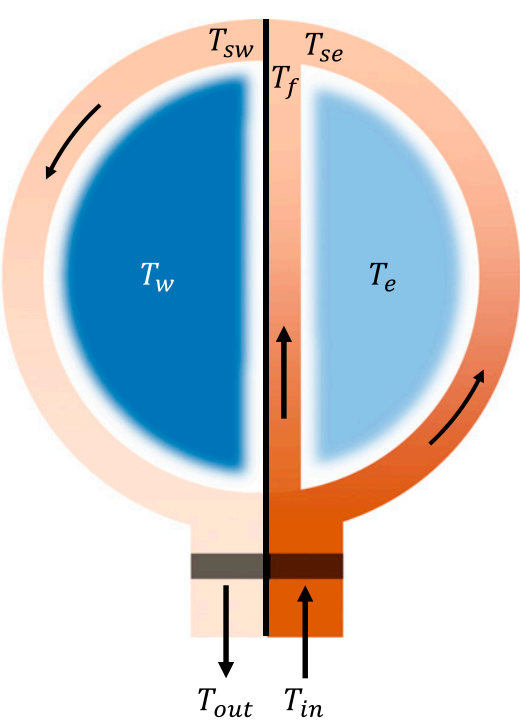

c) 2 basin_full

FIG. 3. Schematic of the conceptual model (a) based on Spall (2011) and extended to a two-basin system (b) without and (c) with a front current; the black vertical line indicates the location of the midocean ridge, and the black horizontal line represents the sill.

derived by taking the difference between the total transport across the transect at $y=700 \mathrm{~km}$ and the slope current transport.

\section{b. A conceptual model with one basin and a single boundary current}

The marginal sea described in Spall (2011) consists of two main regions: the interior and the slope current (hereinafter the 1basin-framework, schematic Fig. 3a). Using simple heat balances, solutions can be found for the interior temperature $T_{0}$ and the temperature of the outflowing water mass $T_{\text {out }}$. A similar approach will be used in section 3 to derive a conceptual model for a twobasin marginal sea. This section summarizes the various assumptions made in Spall (2011) and motivates the extension of the initial 1basin-framework to a two-basin marginal sea.

In the 1basin-framework, the slope current flows around the interior in a cyclonic direction, while losing heat to the atmosphere via surface fluxes and to the interior via eddy fluxes. The mean flow in the interior, where deep convection takes place, is assumed motionless. There, heat lost to the atmosphere is balanced by the lateral eddy heat gain from the buoyant slope current:

$$
\frac{Q_{0}}{\rho_{0} C_{p}}=2 \pi R H F,
$$

where $\rho_{0}$ is the reference density $\left(\mathrm{kg} \mathrm{m}^{-3}\right), C_{p}$ the heat capacity $\left(\mathrm{J} \mathrm{kg}^{-1} \mathrm{~K}^{-1}\right), R$ the radius of the interior basin (m), and $H$ the depth of the slope current (m; reference values for all parameters used in this paper are provided in Table 1). For simplicity, the domain of the marginal sea is assumed to be circular.

The lateral eddy heat flux $F$ in Eq. (2) is parameterized. It is assumed to depend on the baroclinic velocity of the slope current $V_{s}$ and the temperature gradient between the boundary $T_{s}$ and the interior $T_{0}$, following Blumsack and Gierasch (1972) and Spall (2004, 2011):

$$
F=\overline{u^{\prime} T^{\prime}}=c \overline{V_{s}}\left(\overline{T_{s}}-T_{0}\right),
$$

where $c$ is the nondimensional eddy coefficient. The overline refers to the along-flow mean properties of the slope current. The value of the coefficient $c$ depends on the ratio of the isopycnal slope of the slope current and the topographic slope (Blumsack and Gierasch 1972; Spall 2004). Based on the numerical model topography, $c=0.004$ is used for the western basin, where the topographic slope is constant. The choice of $c$ in the eastern basin is not straightforward, as the lower growth rate predicted by the modified Eady theory cannot explain the observed enhanced eddy activity near the steep topographic slope (see discussion in, e.g., Trodahl and Isachsen 2018). Here, we follow the study of Bracco et al. (2008) who suggested that a very steep topographic slope can be seen as a vertical wall. Therefore, we assume that the mean flow in the eastern basin feels a flat bottom, which implies an eddy coefficient $c=0.06$. 
TABLE 1. Input parameters for the conceptual model. Values match the numerical reference simulation described in section $2 \mathrm{a}$ (except for the frontal eddy coefficients $c_{\mathrm{fe}}$ and $c_{\mathrm{fe}}$ ).

\begin{tabular}{lccc}
\hline \hline \multicolumn{1}{c}{ Physical description } & \multicolumn{3}{c}{ Reference } \\
\hline Atmospheric temperature & $T_{A}$ & 4 & ${ }^{\circ} \mathrm{C}$ \\
Inflow temperature & $T_{\mathrm{in}}$ & 9 & ${ }^{\circ} \mathrm{C}$ \\
Depth of currents & $H$ & 650 & $\mathrm{~m}$ \\
Width of currents & $\mathrm{L}$ & $50 \times 10^{3}$ & $\mathrm{~m}$ \\
Basin radius & $R$ & $450 \times 10^{3}$ & $\mathrm{~m}$ \\
Thermal expansion coefficient & $\alpha$ & 0.2 & $\mathrm{~kg} \mathrm{~m}^{-3} \mathrm{~K}^{-1}$ \\
Gravitational acceleration & $g$ & 9.81 & $\mathrm{~m} \mathrm{~s}^{-2}$ \\
Reference density & $\rho_{0}$ & 1028 & $\mathrm{~kg} \mathrm{~m}^{-3}$ \\
Coriolis parameter & $f_{0}$ & $1.2 \times 10^{-4}$ & $\mathrm{~s}^{-1}$ \\
Eddy coefficient east & $c_{e}$ & 0.06 & - \\
Eddy coefficient west & $c_{w}$ & 0.004 & - \\
Eddy coefficient front to & $c_{\mathrm{fe}}$ & 0.06 & - \\
$\quad$ the east & & & \\
Eddy coefficient front to & $c_{\mathrm{fw}}$ & 0.004 & - \\
$\quad$ the west & & & \\
Restoring strength & $\Gamma$ & 16 & $\mathrm{~W} \mathrm{~m}^{-2} \mathrm{~K}^{-1}$ \\
Heat capacity & $C_{p}$ & 3994 & $\mathrm{~J} \mathrm{~kg}^{-1} \mathrm{~K}^{-1}$ \\
\hline
\end{tabular}

Similar to the numerical simulations, the total surface heat loss $Q_{0}(\mathrm{~W})$ is given by

$$
Q_{0}=A_{0} \Gamma\left(T_{0}-T_{A}\right) .
$$

Here, $A_{0}$ is the area of the interior exposed to the atmosphere $\left(\mathrm{m}^{2}\right)$.

Next, a heat balance for the slope current is defined. It is assumed that the downstream change in heat transport is governed by the surface heat loss to the atmosphere $Q_{s}$ across the slope current and the lateral eddy heat flux to the interior:

$$
\Psi_{s}\left(T_{\text {in }}-T_{\text {out }}\right)=\frac{Q_{s}}{\rho_{0} C_{p}}+2 \pi R H F=\frac{Q_{s}}{\rho_{0} C_{p}}+\frac{Q_{0}}{\rho_{0} C_{p}} .
$$

The heat loss $Q_{s}$ is defined analogous to Eq. (4), using $T_{s}$ and $A_{s}=2 \pi R L$, with $L$ the width of the slope current $(\mathrm{m})$. The slope current is assumed to be in geostrophic balance, so $\Psi_{s}\left(\mathrm{~m}^{3} \mathrm{~s}^{-1}\right)$ is given by

$$
\Psi_{s}=\frac{\alpha g H^{2}}{2 \rho_{0} f_{0}}\left(T_{s}-T_{0}\right)=\overline{V_{s}} H L .
$$

Here, $\alpha$ is the thermal expansion coefficient $\left(\mathrm{kg} \mathrm{m}^{-3} \mathrm{~K}^{-1}\right)$, $f_{0}$ the Coriolis parameter $\left(\mathrm{s}^{-1}\right)$ and $g$ the gravitational acceleration $\left(\mathrm{m} \mathrm{s}^{-2}\right)$. The derivation of the 1basinframework is based solely on the description of baroclinic currents as we consider wind forcing only implicitly (by homogenizing water masses and maintaining a level of no motion). The possible impact of the winds on the buoyancy budgets derived in this paper will be discussed in section 5 .
TABLE 2. Nondimensional parameters.

\begin{tabular}{lcc}
\hline \multicolumn{1}{c}{ Physical description } & Symbol & Equation \\
\hline Atmospheric forcing efficiency & $\mu$ & $\Gamma f_{0} /\left[\alpha g C_{p}\left(T_{\text {in }}-T_{A}\right)\right]$ \\
Eddy efficiency & $\varepsilon$ & $c R / L$ \\
Aspect ratio & $\delta$ & $H^{2} / R^{2}$ \\
\hline
\end{tabular}

To allow the derivation of an analytical solution for both the temperature of the interior and the temperature of the outflowing water mass $\left(T_{0}\right.$ and $\left.T_{\text {out }}\right)$, Spall (2011) assumes that the temperature of the slope current $T_{s}$ is constant and equal to the inflow temperature $T_{\mathrm{in}}$. Solutions for $T_{0}$ and $T_{\text {out }}$ can then be found by combining Eqs. (2)-(6):

$$
\begin{aligned}
T_{\text {in }}-T_{0} & =\frac{\mu}{2 \delta \varepsilon}\left[\left(1+\frac{4 \delta \varepsilon}{\mu}\right)^{1 / 2}-1\right]\left(T_{\text {in }}-T_{A}\right), \\
T_{\text {in }}-T_{\text {out }} & =\frac{2 \pi \mu}{\delta}\left[\frac{T_{\text {in }}-T_{A}}{T_{\text {in }}-T_{0}}\left(1+\frac{2 L}{R}\right)-1\right]\left(T_{\text {in }}-T_{A}\right) .
\end{aligned}
$$

Three nondimensional parameters have been introduced in Eq. (7) (see Table 2). The parameter $\mu$ (hereinafter the atmospheric forcing efficiency) and the parameter $\varepsilon$ (hereinafter the eddy efficiency) are both a measure of how effectively heat is extracted from the system, either based on the strength of the air-sea exchange coefficient $\Gamma$ or on the eddy coefficient $c$. Their ratio indicates the dominance of the atmospheric influence relative to the lateral eddy advection on the resulting interior and outflow temperature. These parameters are used to investigate what controls the mean hydrography and volume transport in the marginal sea. In this study, the choice is made to describe the basin geometry solely by the radius $R$ [instead of by the surface area and perimeter as used in Spall (2011)]. Therefore, Eq. (7) and the nondimensional parameters are slightly different. Moreover, an additional "aspect ratio" parameter $\delta$ is introduced.

The solutions provided by Eq. (7) are identical to the equations derived in Spall [2011, his Eqs. (8) and (17)] and the response of the dynamics of this marginal sea to changes in the atmospheric forcing or eddy fluxes (by changing $\mu$ or $\varepsilon$ ) are discussed in detail by Spall (2011). One of the key implications of the 1basin-framework is that the sensitivity of the marginal sea to atmospheric forcing depends on the relative strength of the eddy fluxes compared to the surface fluxes. For example, the Lofoten Basin (hereinafter the eastern basin) is characterized by a large eddy heat flux from the boundary to the interior due to the increased instability of the slope current near the Lofoten Islands. This basin, as discussed 
by Spall (2011), is typically in an eddy-dominated regime $(\mu / \varepsilon \ll 1)$, meaning that the basin is characterized by very efficient lateral heat transport to compensate for the surface heat loss. In contrast, in the Greenland Basin (hereinafter the western basin) the lateral heat transport from the boundary to the interior is less strong ( $c$ is small).

As a consequence, the interior basin temperature $T_{0}$ is more sensitive to changes in atmospheric forcing in the western basin (blue line in Fig. 4) than in the eastern basin (red line in Fig. 4). The following section will extend the 1basin-framework to a twobasin marginal sea that combines the eddy-dominated eastern basin and the atmosphere-dominated western basin.

\section{Conceptual model for a two-basin marginal sea}

A stepwise approach is taken to extend the 1basinframework [Eq. (7)] to a 2basin-framework. As a first step, the eastern and western basin are treated as two separate basins (schematic Fig. 3b), where the outflow of the eastern basin is connected to the inflow of the western basin. Results of this approach are discussed in section $3 a$. Section $3 b$ further extends the framework by adding a front current and by allowing a gradual cooling of the slope and front current in the downstream direction (schematic Fig. 3c).

\section{a. A two-basin approach without a front current}

As a first step toward a conceptual model for a twobasin marginal sea, the set of solutions given by the 1basin-framework is applied twice; once for a basin applying a large eddy coefficient (the eastern basin) and once for a basin applying a small eddy coefficient (the western basin). The temperature of the outflow from the eastern basin is then simply used as the inflow temperature for the western basin (representing the recirculating Atlantic Water). This setup, the 2basin_simple-framework, is schematized in Fig. $3 \mathrm{~b}$. Following this approach, the solutions for the interior temperature in the east $T_{e}$ and west $T_{w}$ and for the flow from the east into the west $T_{\text {in }}^{\star}$ and out of the western basin $T_{\text {out }}$ are given by Eq. (8):

For the eastern basin,

$$
\begin{aligned}
& T_{\text {in }}-T_{e}=\frac{\mu}{2 \delta \varepsilon_{e}}\left[\left(1+\frac{4 \delta \varepsilon_{e}}{\mu}\right)^{1 / 2}-1\right]\left(T_{\mathrm{in}}-T_{A}\right), \\
& T_{\text {in }}-T_{\text {in }}^{\star}=\frac{\pi \mu}{\delta}\left[\frac{T_{\text {in }}-T_{A}}{T_{\text {in }}-T_{e}}\left(1+\frac{2 L}{R}\right)-1\right]\left(T_{\text {in }}-T_{A}\right),
\end{aligned}
$$

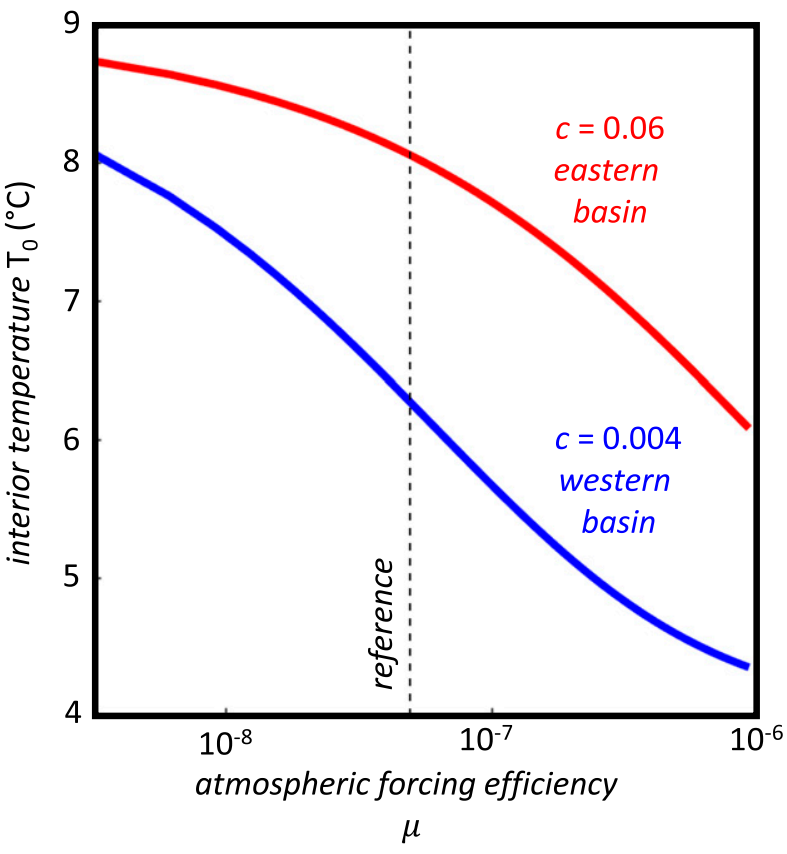

FIG. 4. The interior basin temperature $T_{0}$ as a function of the nondimensional parameter $\mu$ for a basin with a large eddy coefficient $(c=0.06$, red line $)$ and for a basin with a small eddy coefficient ( $c=0.004$, blue line) using the 1 basin-framework. Input parameters used for the calculation are given in Table 1 . The vertical dashed line indicates the value of the nondimensional parameter $\mu$ that corresponds to the reference model simulation. Values of $c$ used for the eastern basin and for the western basin are estimated based on the steepness of the slope in these basins in the numerical simulations.

and for the western basin,

$$
\begin{aligned}
T_{\text {in }}^{\star}-T_{w}= & \frac{\mu}{2 \delta \varepsilon_{w}}\left[\left(1+\frac{T_{\text {in }}^{\star}-T_{A}}{T_{\text {in }}-T_{A}} \frac{4 \delta \varepsilon_{w}}{\mu}\right)^{1 / 2}-1\right] \\
& \times\left(T_{\text {in }}-T_{A}\right), \\
T_{\text {in }}^{\star}-T_{\text {out }}= & \frac{\pi \mu}{\delta}\left[\frac{T_{\text {in }}^{\star}-T_{A}}{T_{\text {in }}^{\star}-T_{w}}\left(1+\frac{2 L}{R}\right)-1\right]\left(T_{\text {in }}-T_{A}\right) .
\end{aligned}
$$

Note that $T_{\text {in }}$ is now the temperature of the slope current in the east (equal to $T_{s}$ ). Instead of $T_{\text {out }}$ as used in Eq. (7), $T_{\text {in }}^{\star}$ is the temperature of the outflow from the eastern basin [Eq. (8b)] and at the same time the temperature of the boundary current in the west (Fig. 3b). Therefore, in Eqs. (8c) and (8d), $T_{\text {in }}$ from Eq. (7) is replaced by $T_{\text {in }}^{\star}$. As the $\mu$ parameter also depends on $T_{\text {in }}$ (Table 2), an additional term $\left(T_{\text {in }}^{\star}-T_{A}\right) /\left(T_{\text {in }}-T_{A}\right)$ appears in Eq. (8c).

The subscript of the $\varepsilon$ parameter in Eq. (8) indicates whether the eddy coefficient of the eastern or the 


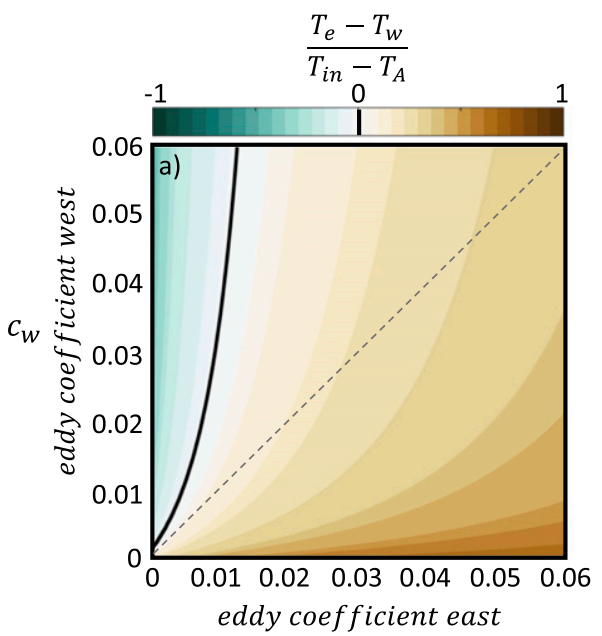

$c_{e}$

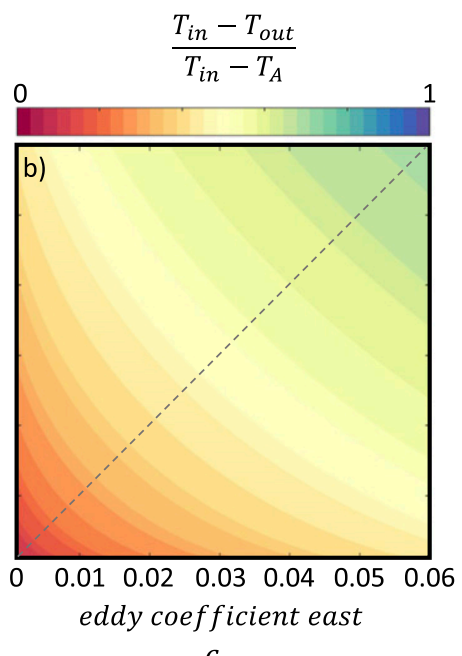

$c_{e}$

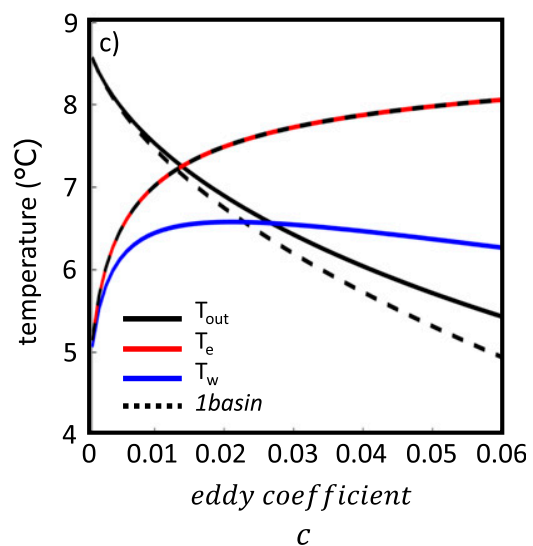

$C$

FIG. 5. Nondimensional temperature difference between (a) the eastern and western basin and (b) the outflow and inflow as a function of the eddy coefficient in the east $c_{e}$ and in the west $c_{w}$ for the 2basin_simple-framework. In (b) red shading indicates a warm outflow and blue shading indicates a cold outflow. (c) The temperature of the eastern basin interior (red line), the western basin interior (blue line), and the outflow (black line) as a function of the eddy coefficient $\left(c=c_{w}=c_{e}\right)$ for the 2basin_simple-framework. The dashed lines show the solutions from the 1basin-framework.

western basin is used $\left(c_{e}\right.$ or $\left.c_{w}\right)$. Using the 2basin_simple-framework, most combinations of $c_{e}$ and $c_{w}$ result in a warmer eastern basin than western basin (brown shading in Fig. 5a). This is because the slope current in the east is always warmer than the slope current in the west $\left(T_{\text {in }}>T_{\text {in }}^{\star}\right)$. Therefore, even for equal eddy coefficients (Fig. $5 \mathrm{c}$ ), the lateral heat flux from the boundary to the interior is larger in the eastern basin.

Increasing $c_{e}$ leads to an increase in the temperature difference between east and west. This is not only because the interior basin temperature in the east increases, but also because the interior basin temperature in the west decreases. The temperature change in the eastern basin is as expected, as the lateral eddy heat flux from the boundary current into the eastern basin increases. Since the eastern slope current has lost more heat to the interior, the slope current of the western basin will be colder and therefore the lateral heat exchange with the western basin interior reduces. So, the eddy efficiency in the eastern basin not only affects the eastern basin interior temperature, but also the interior temperature of the downstream basin. This conclusion does not hold for changes in $c_{w}$, as in the 2basin_simpleframework $c_{w}$ can only impact the western basin interior and the temperature of the outflow.

The sensitivity of the outflow temperature to the eddy coefficients is as expected; for large $c$, the boundary current loses more heat, and the temperature of the outflow is reduced (upper right corner Fig. 5b). The 2basin_simple-framework estimates a warmer outflowing water mass than the 1basin-framework (cf. solid and dashed black lines Fig. 5c). The reason is that due to the lack of a second basin in the 1basin-framework, the slope current retains a constant temperature everywhere ( $\operatorname{similar}$ to $T_{\text {in }}=T_{\text {in }}^{\star}$ ). Therefore, more heat is lost to the interior in the 1basin-framework, which results in a colder outflow compared to the 2basin_simple-framework.

\section{b. A two-basin approach with a front current}

The 2basin_simple-framework, using two separate basins representing the Lofoten Basin and the Greenland Basin, already indicates that the dynamics in the upstream basin influence the dynamics in the downstream basin. However, there are two important features that are missing in this simple approach. First, in the Nordic seas there are two pathways for northward heat transport: the slope current along the continental margin and the front current along the midocean ridge. Therefore, not only the slope current, but also the front current can exchange heat with the interior via lateral eddy heat fluxes. Furthermore, the conceptual models described so far assume that the slope current retains a constant temperature. As seen in Fig. 2a, this is not an appropriate assumption; much of the heat is already lost before the slope current enters the western side of the basin. This section will implement these components by introducing a front current and a gradual cooling of both the slope current and the front current. This way, the 2basin_full-framework is derived that provides valuable insight in the dynamics of a two-basin marginal sea like the Nordic seas. A schematic of this system is shown in Fig. 3c. 
Using similar heat balances as described in section $2 \mathrm{~b}$, a set of six equations is derived that can be solved for the interior temperature of the eastern and western basin ( $T_{e}$ and $\left.T_{w}\right)$, the temperature of the front current $\left(T_{f}\right)$, the temperature of the boundary current in the east $\left(T_{\mathrm{se}}\right)$, the temperature of the boundary current in the west $\left(T_{\mathrm{sw}}\right)$, and the temperature of the outflowing water mass ( $T_{\text {out }}$, see Fig. $3 \mathrm{c}$ for locations). The set of equations only has solutions for $T_{e}>T_{w}$, which is the case in the Nordic seas.

In the interior of the basins, the heat lost to the atmosphere is now balanced by the heat gained by lateral heat fluxes not only from the boundary current, but also from the front current [analogous to Eq. (2)]:

$$
\begin{gathered}
\frac{Q_{e}}{\rho_{0} C_{p}}=\pi R H F_{\mathrm{se}}+2 R H F_{\mathrm{fe}}, \\
\frac{Q_{w}}{\rho_{0} C_{p}}=\pi R H F_{\mathrm{sw}}+2 R H F_{\mathrm{fw}} .
\end{gathered}
$$

The subscripts either refer to the slope current along the eastern boundary (se), the slope current along the western boundary (sw) or the front current (f). Two new free parameters, the frontal eddy coefficients, are introduced as the front current can exchange heat in two directions: to the east (subscript fe) and to the west (subscript fw). As we are interested in the strength of the heat flux from the front current, rather than the underlying dynamics of the instability of a front along a midocean ridge, we choose the frontal eddy coefficients $\left(c_{\mathrm{fe}}\right.$ and $\left.c_{\mathrm{fw}}\right)$ such to find closest agreement with the interior basin temperatures given by the numerical simulations (see Table 1). Sensitivity of the results to changes in the frontal eddy coefficients is discussed at the end of this section.

In addition to Eq. (9) for the interior basin temperatures, three equations for the heat balance are derived for the eastern slope current, the western slope current and the front current respectively [analogous to Eq. (5)]:

$$
\begin{aligned}
\Psi_{\mathrm{se}}\left(T_{\mathrm{in}}-T_{\mathrm{se}}\right) & =\frac{Q_{\mathrm{se}}}{\rho C_{p}}+\pi R H F_{\mathrm{se}}, \\
\Psi_{\mathrm{sw}}\left(T_{\mathrm{sw}}-T_{\mathrm{out}}\right) & =\frac{Q_{\mathrm{sw}}}{\rho C_{p}}+\pi R H F_{\mathrm{sw}}, \quad \text { and } \\
\Psi_{f}\left(T_{\mathrm{in}}-T_{f}\right) & =\frac{Q_{f}}{\rho C_{p}}+2 R H F_{\mathrm{se}}+2 R H F_{\mathrm{fw}} .
\end{aligned}
$$

To close the set of equations, conservation of mass and heat is applied in the northernmost point, where the slope current and front current merge:

$$
\begin{gathered}
\Psi_{\mathrm{in}}=\Psi_{\mathrm{out}}=\Psi_{\mathrm{sw}}=\Psi_{\mathrm{se}}+\Psi_{f}, \\
\Psi_{\mathrm{se}} T_{\mathrm{se}}+\Psi_{f} T_{f}=\Psi_{\mathrm{sw}} T_{\mathrm{sw}} .
\end{gathered}
$$

For the 2basin_full-framework we assume that the slope current and the front current have equal width $L$ (see discussion in section 5) and we again assume that both currents are in thermal wind balance with zero velocity at a given depth $H$ :

$$
\begin{aligned}
& \Psi_{\mathrm{se}}=\frac{\alpha g H^{2}}{2 \rho_{0} f_{0}}\left(T_{\mathrm{in}}-T_{e}\right), \\
& \Psi_{f}=\frac{\alpha g H^{2}}{2 \rho_{0} f_{0}}\left[\left(\overline{T_{f}}-T_{w}\right)-\left(\overline{T_{f}}-T_{e}\right)\right]=\frac{\alpha g H^{2}}{2 \rho_{0} f_{0}}\left(T_{e}-T_{w}\right) .
\end{aligned}
$$

Combining Eqs. (9)-(12), substituting equations for the heat flux to the atmosphere, the eddy parameterization [Eqs. (4) and (3), respectively] and the nondimensional parameters (Table 2), six equations are derived for the interior temperature in the eastern and western basin $\left(T_{e}\right.$ and $\left.T_{w}\right)$, the final temperature of the currents $\left(T_{\mathrm{se}}, T_{f}\right.$, and $\left.T_{\text {out }}\right)$ and the starting temperature of the western boundary current $\left(T_{\mathrm{sw}}\right)$. The resulting set of equations for the 2basin_full is given by Eq. (13). In these equations, the overline refers to the along-flow mean temperature of the flow.

Equation for $T_{e}$ :

$$
\begin{aligned}
T_{e}-T_{A}= & \frac{\varepsilon_{e} \delta}{\mu\left(T_{\mathrm{in}}-T_{A}\right)}\left(T_{\mathrm{in}}-T_{e}\right)\left(\overline{T_{\mathrm{se}}}-T_{e}\right) \\
& +\frac{2 \varepsilon_{\mathrm{fe}} \delta}{\pi \mu\left(T_{\mathrm{in}}-T_{A}\right)}\left(\overline{T_{f}}-T_{e}\right)^{2} .
\end{aligned}
$$

Equation for $T_{w}$ :

$$
\begin{aligned}
T_{w}-T_{A}= & \frac{\varepsilon_{w} \delta}{\mu\left(T_{\mathrm{in}}-T_{A}\right)}\left(T_{\mathrm{in}}-T_{w}\right)\left(\overline{T_{\mathrm{sw}}}-T_{w}\right) \\
& +\frac{2 \varepsilon_{\mathrm{fw}} \delta}{\pi \mu\left(T_{\mathrm{in}}-T_{A}\right)}\left(\overline{T_{f}}-T_{w}\right)^{2} .
\end{aligned}
$$

Equation for $T_{\mathrm{se}}$ :

$$
\begin{aligned}
T_{\text {in }}-T_{\mathrm{se}}= & \frac{\pi \mu}{\delta} \frac{\left(T_{\mathrm{in}}-T_{A}\right)\left(\overline{T_{\mathrm{se}}}-T_{A}\right)}{\left(T_{\mathrm{in}}-T_{e}\right)} \frac{2 L}{R} \\
& +\pi \varepsilon_{e}\left(\overline{T_{\mathrm{se}}}-T_{e}\right) .
\end{aligned}
$$

Equation for $T_{\text {out }}$ :

$$
\begin{aligned}
T_{\mathrm{sw}}-T_{\mathrm{out}}= & \frac{\pi \mu}{\delta} \frac{\left(T_{\mathrm{in}}-T_{A}\right)\left(\overline{T_{\mathrm{sw}}}-T_{A}\right)}{\left(T_{\mathrm{in}}-T_{w}\right)} \frac{2 L}{R} \\
& +\pi \varepsilon_{w}\left(\overline{T_{\mathrm{sw}}}-T_{w}\right) .
\end{aligned}
$$


Equation for $T_{f}$ :

$$
\begin{aligned}
T_{\text {in }}-T_{f}= & \frac{2 \mu}{\delta} \frac{\left(T_{\mathrm{in}}-T_{A}\right)\left(\overline{T_{f}}-T_{A}\right)}{\left(T_{e}-T_{w}\right)} \frac{2 L}{R}+2 \varepsilon_{\mathrm{fe}} \frac{\left(\overline{T_{f}}-T_{e}\right)^{2}}{T_{e}-T_{w}} \\
& +2 \varepsilon_{\mathrm{fw}} \frac{\left(\overline{T_{f}}-T_{w}\right)^{2}}{T_{e}-T_{w}} .
\end{aligned}
$$

Equation for $T_{\mathrm{sw}}$ :

$$
\left(T_{\mathrm{in}}-T_{e}\right)\left(T_{\mathrm{se}}-T_{\mathrm{sw}}\right)=\left(T_{e}-T_{w}\right)\left(T_{\mathrm{sw}}-T_{f}\right) .
$$

The first two equations provide estimates for the eastern and western interior basin temperature. Just as for the 1basin- and 2basin_simple-frameworks, the interior basin temperature depends on the ratio $\mu / \varepsilon$. However, the resulting temperature does not only depend on the relative importance of the atmosphere and the lateral eddy heat flux from the boundary current [first term on the right-hand side of Eqs. (13a) and (13b)] but also on the ratio of the atmospheric forcing efficiency and the eddy heat flux from the front current [second term on the right-hand side of Eqs. (13a) and (13b)]. Equations (13c)-(13e) provide estimates for the slope currents and front current, where the first term on the right hand side indicates the temperature change due to heat loss to the atmosphere and the second [and third, Eq. (13e)] represent the temperature change due to the lateral eddy heat flux.

Some insight into the 2basin_full-framework is obtained by investigating the limits of $\mu / \varepsilon$, but keeping in mind that there are now four different eddy efficiency parameters: $\varepsilon_{e}, \varepsilon_{w}, \varepsilon_{\mathrm{fe}}$, and $\varepsilon_{\mathrm{fw}}$. We consider the case where the eddy coefficients from the front are very small, and the eddy coefficients from the eastern and western boundary current are equal. In case the atmospheric forcing is relatively strong $(\mu / \varepsilon \gg 1)$, both $T_{e}$ and $T_{w}$ approach the temperature of the atmosphere [Eqs. (13a) and (13b)]. As a result, the temperature difference between east and west becomes very small, which means that the front current transport is weak [Eq. (12b)]. Following Eq. (13f) (the conservation of heat in the northernmost point) the end temperature of the slope current in the east $T_{\mathrm{se}}$ will approach the starting temperature of the slope current in the west $T_{\mathrm{sw}}$. Therefore, under these circumstances the 2basin_full-framework reduces to the 1 basin-framework, but now including a linear change of the boundary current temperature.

The sensitivity changes when the system is in a weaker atmospheric forcing regime $(\mu / \varepsilon \ll 1)$. Still considering the case where $c_{e}=c_{w}$ (and $\left.c_{\mathrm{fe}}=c_{\mathrm{fw}}=0\right)$, the interior basin temperature now mainly depends on the difference

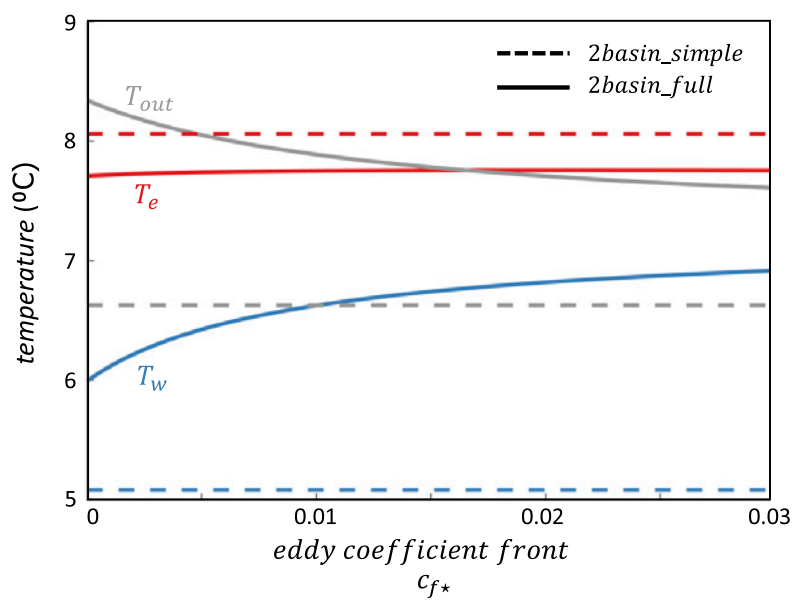

FIG. 6. Temperature of the eastern interior $T_{e}$, the western interior $T_{w}$, and the outflowing water mass $T_{\text {out }}$ as a function of the frontal eddy coefficient for the 2basin_full-framework (solid lines) and the 2basin_simple-framework (dashed lines). The $c_{\mathrm{fe}}$ and $c_{\mathrm{fw}}$ parameter are equal and represented by $c_{f \star}$ for this calculation.

in temperature between the slope current and the interior in these basins [Eqs. (13a) and (13b)]. As the boundary current in the east is warmer than in the west, just as for the 2basin_simple-framework, the lateral heat flux from the eastern boundary into the eastern interior basin will be larger than in the west, even for equal eddy coefficients. However, comparison of the results from the 2basin_full-framework and the 2basin_simpleframework (Fig. 6) shows a large disagreement between the estimated temperatures, even if $c_{\mathrm{fe}}=c_{\mathrm{fw}}=0$ (cf. solid and dashed lines). Particularly the estimated western basin interior temperature and the temperature of the outflow are lower $\left(\Delta T>1^{\circ} \mathrm{C}\right)$ in the 2basin_simple-framework compared to the 2basin_fullframework (gray and blue lines in Fig. 6). There are two reasons for this difference.

First, in the 2basin_full-framework, the boundary currents and the front current change their temperature linearly in the downstream direction, whereas in the 2basin_simple-framework these are equal to their upstream values and hence warmer. Therefore, the heat lost to the atmosphere via surface fluxes and the heat lost to the interior via the lateral eddy heat fluxes are much larger in the 2basin_simple-framework than in the 2basin_full-framework, leading to lower estimates for the temperature of the outflow. Second, in the 2basin_full-framework the temperature at the upstream end of the boundary current in the west $T_{\mathrm{sw}}$ does not only depend on the downstream temperature of the boundary current in the east $T_{\mathrm{se}}$, but also on the downstream temperature of the front current $T_{f}$. Especially for small frontal eddy coefficients this leads to a larger $T_{\mathrm{sw}}$, as the front current heat loss is minimal. Additionally, when 
the frontal eddy coefficients are nonzero, the lateral eddy heat flux to the interior of the western basin comes not only from the boundary current in the west (like in the basin_simple-framework), but also from the front current. This leads to an even larger discrepancy between the estimated western basin interior temperatures (blue lines Fig. 6).

In the 2basin_full-framework, the western basin interior (blue line) is more sensitive to changes in $c_{f}$ than the eastern basin interior (red line), as the temperature difference between the front current and the western basin interior is always larger than the temperature gradient between the front and the eastern basin interior. However, overall the temperatures of the interior basins and the outflow seem relatively insensitive to changes in $c_{f}$ (especially for $c_{f}>0.01$ ).

Results from the 2basin_full-framework show that the implementation of a gradual downstream cooling of the slope current and front current is at least as important for the estimated temperatures as the implementation of the frontal dynamics. The next section will show that, as a result of these implementations, the 2basin_full-framework is able to capture the dynamics of the numerical two-basin simulations better than the 2basin_simple-framework.

\section{Sensitivity to atmospheric buoyancy forcing}

As discussed in section $2 b$, the Lofoten Basin is less sensitive to changes in atmospheric forcing than the Greenland Basin due to the different eddy fluxes from the boundary current. In the 2basin_full-framework these two basins are connected via the slope current and via the front current. Therefore, the response of the whole system to changes in atmospheric forcing is expected to be not only nonuniform, but also nonlinear.

To test this hypothesis, the solutions from the 1basin-framework, the 2basin_simple-framework and the 2basin_full-framework are compared to the numerical simulations described in section 2 a for different values of the nondimensional parameter $\mu$ (the measure of the atmospheric forcing efficiency). In the numerical simulations, the parameter $\mu$ is varied by changing the restoring strength $\Gamma$ (see Table 3 , run 1-7). We choose to change $\Gamma$ and not $T_{A}$, as changes in $T_{A}$ only set the scale of possible solutions $\left(T_{A}<T<T_{\text {in }}\right)$, whereas changes in $\Gamma$ provide insight into what controls the dynamics in the marginal sea. Sensitivity studies to a change in $T_{A}$ have been performed but did not lead to different insights than discussed in this section (not shown).

The numerical simulations, the 2basin_full- and the 2basin_simple-frameworks all show, in contrast with the 1basin-framework, that the temperature change of
TABLE 3. Key parameters of the numerical model sensitivity analysis. Bold values indicate the key parameters of the reference simulation.

\begin{tabular}{cccl}
\hline \hline Run & $\Gamma\left(\mathrm{W} \mathrm{m}^{-2}{ }^{\circ} \mathrm{C}^{-1}\right)$ & $\mu\left(\times 10^{-8}\right)$ & Symbol \\
\hline 1 & 4 & 1.2 & Square \\
2 & 8 & 2.5 & Square \\
$\mathbf{3}$ & $\mathbf{1 6}$ & $\mathbf{4 . 9}$ & Star \\
4 & 32 & 9.8 & Square \\
5 & 64 & 19.6 & Square \\
6 & 128 & 39.2 & Square \\
7 & 256 & 78.4 & Square \\
\hline
\end{tabular}

the two-basin marginal sea is nonuniform when a uniform change in atmospheric forcing is applied (expressed by the nondimensional parameter $\mu$, Fig. 7a). The temperature difference between the eastern and western basin interior displays a maximum for $\mu \sim 2 \times$ $10^{-7}$ for both the 2basin_full-framework (solid line in Fig. 7a) and the simulations (squares in Fig. 7a). For small values of $\mu$, the resulting atmospheric cooling is minimal (Fig. 7c), so both the eastern and western basins remain warm and the temperature gradient is therefore small (Fig. 7a). For large values of $\mu$, both the basins will cool toward the prescribed atmospheric temperature $T_{A}$. Therefore, for strong atmospheric forcing, the temperature gradient between east and west will be small as well. A more realistic case lies between these two limits (see star symbol for the reference simulation in Fig. 7a), where the temperature decrease in the western basin is larger than in the eastern basin (Fig. 4), due to the combined effect of a colder boundary current in the west and a weaker eddy flux from the boundary to the western basin interior.

The dependence of the estimated temperatures on the change in atmospheric forcing is quite similar for the 2basin_full-framework and the 2basin_simple-framework (Figs. 7a-c). However, the 2basin_full-framework shows much better agreement with the numerical simulations. Again, the 2basin_simple-framework underestimates the temperature of the western basin (explaining the much larger temperature difference found in Fig. 7a), the temperature of the outflow and the total heat loss to the atmosphere (dashed lines in Figs. 7b,c). As discussed in section $3 b$, this is because the equations describing the 2basin_simple-framework neither incorporate the eddy heat flux from the front current into the western basin interior, nor the downstream cooling of the boundary currents. The 1 basin-framework can only provide solutions for a basin with a constant eddy coefficient and comes nowhere near the results from the numerical simulations; where the estimated temperature of the outflow using $c_{w}$ is rather well captured, using the same eddy coefficient, the sensitivity of the total heat flux to 

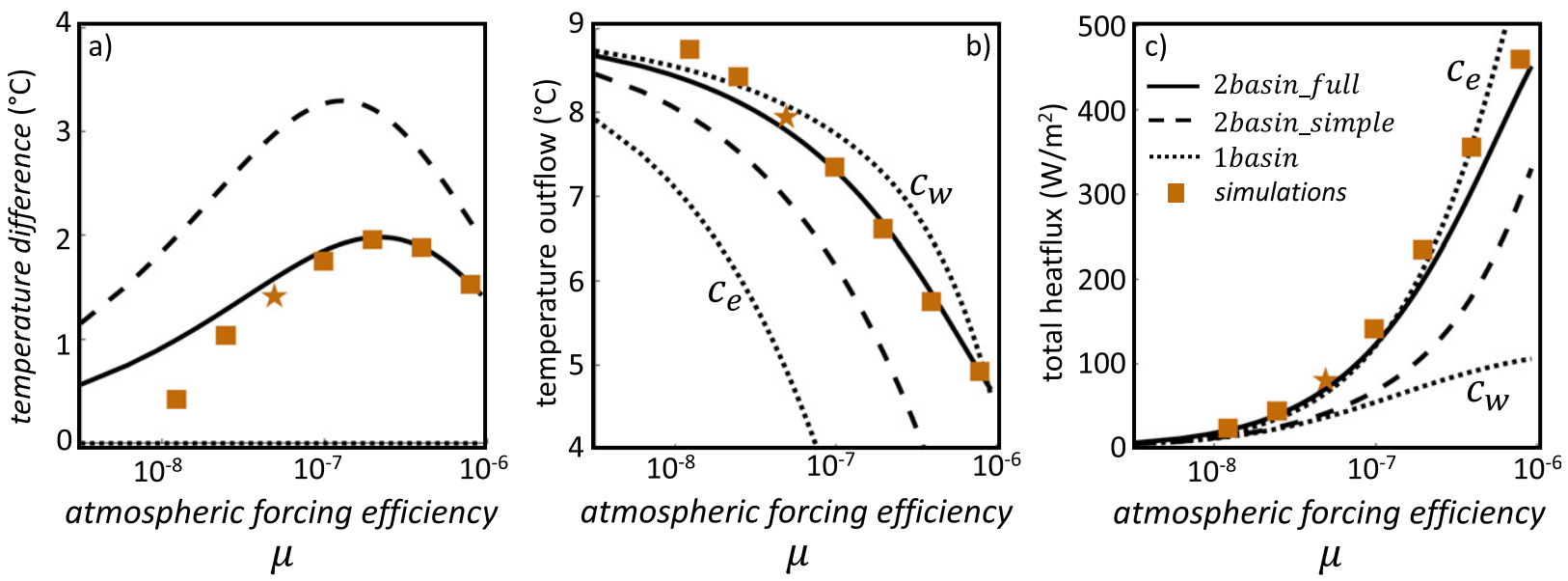

FIG. 7. (a) Mean temperature difference between the eastern and western basins, (b) the temperature of the outflowing water mass, and (c) the total heat loss to the atmosphere as a function of the nondimensional parameter $\mu$. The temperatures and heat flux shown are diagnosed from the 2basin_full-framework (solid lines), from the 2basin_simple-framework (dashed lines), and from the numerical simulations (orange markers). Solutions from the 1basin-framework using either the value of $c_{e}$ or $c_{w}$ are shown as well (dotted lines). The star indicates the reference simulation. Note that the horizontal axis is logarithmic.

changes in atmospheric forcing is strongly underestimated (dotted lines Figs. 7b,c).

The nonlinear response of the temperature gradient between the eastern and western basins to changes in atmospheric forcing seen in Fig. 7a has implications for the dynamics in the two-basin marginal sea. In the 2basin_full-framework, the heat balance derived for each current implies that the total heat transported into the marginal sea is equal to the total amount of heat lost to the atmosphere [Eq. (10)]. Since $T_{\text {in }}$ is kept constant, the inflow $\Psi_{\text {in }}$ increases when the atmospheric forcing is stronger (solid line in Fig. 8a). The results from the numerical simulations corroborate this relation between the heat loss and the inflow (squares in Fig. 8a).

In the 2basin_full-framework the inflow separates in the front current and the slope current along the eastern boundary [see Eq. (11)]. Furthermore, the strength of the front current is set by the temperature difference between the eastern and western basin [see Eq. (12)]. Therefore, the volume transports along the front current $\Psi_{f}$ and along the slope current in the east $\Psi_{\text {se }}$ are codependent, both on the total heat loss to the atmosphere and on the temperature gradient between the eastern and western basins (solid lines in Figs. 8b,c). This provides a dynamical explanation for the observed anticorrelation between the Atlantic Water transport along the front current and the slope current.

The magnitude of the volume transport for the slope current and the front current diagnosed from the numerical simulations and its response to changes in atmospheric forcing are captured well by the 2basin_full-framework (cf. squares and solid lines in Figs. 8b,c). This indicates that the dynamics in the numerical simulations match the assumptions made in the conceptual model. However, for small values of $\mu$ the numerical simulations predict larger volume transports of the slope current (Fig. 8b). One possible explanation for this discrepancy is the artificial restoring region in the numerical simulations, where not only temperature, but also the velocity is prescribed. Therefore, the numerical simulations might overestimate the volume transport into the marginal sea for relatively weak atmospheric forcing. This prescribed velocity also impacts the temperatures of the interior basins and the outflow, which are all slightly warmer than the 2basin_full-framework predicts for weak atmospheric forcing (Figs. 7a,b). However, the only forcing mechanism in the conceptual model is the pull of warm water into the Nordic seas from heat loss to the atmosphere as assumed in, for example, Spall (2011). So, the conceptual model could also underestimate the transport of the inflow, as for example the role of wind forcing is neglected (see, e.g., Orvik and Skagseth 2005; Sand $\varnothing$ and Furevik 2008). The overestimation of the volume transport in the numerical simulations could then be interpreted as a minimal inflow transport from a wind-driven circulation.

So far, we have shown that a two-basin approach leads to a nonlinear response of the marginal sea to changes in atmospheric forcing. The temperature gradient between the eastern and western basins (and as such the strength of the front current) can either increase or decrease for the same change in $\mu$ depending on whether the atmospheric forcing is strong or weak (Figs. $7 \mathrm{a}$ and $8 \mathrm{c}$ ). To be able to predict which response can be expected, some insight in the dependence of $\mu_{\max }$ ( $\mu$ for which the 

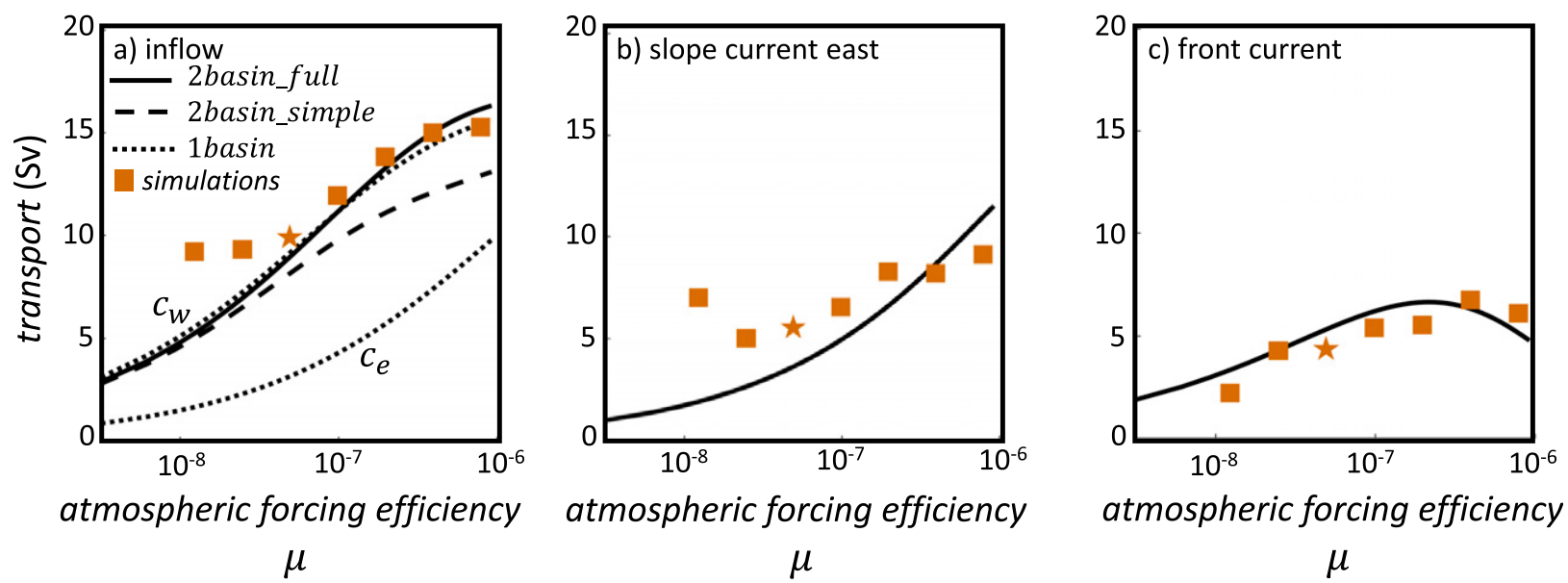

FIG. 8. As in Fig. 7, but now for the estimated volume transport ( $\mathrm{Sv} ; 1 \mathrm{~Sv} \equiv 10^{6} \mathrm{~m}^{3} \mathrm{~s}^{-1}$ ) of (a) the inflow $\Psi_{\text {in }}$, (b) the eastern slope current $\Psi_{\mathrm{se}}$, and (c) the front current $\Psi_{f}$.

maximum temperature gradient is found) on the eddy coefficients is required.

The 2basin_full-framework predicts a similar sensitivity of the temperature difference to the eddy coefficients as discussed in section 2 b (Fig. 5) for the 2basin_simpleframework; increasing the eddy coefficient in the east

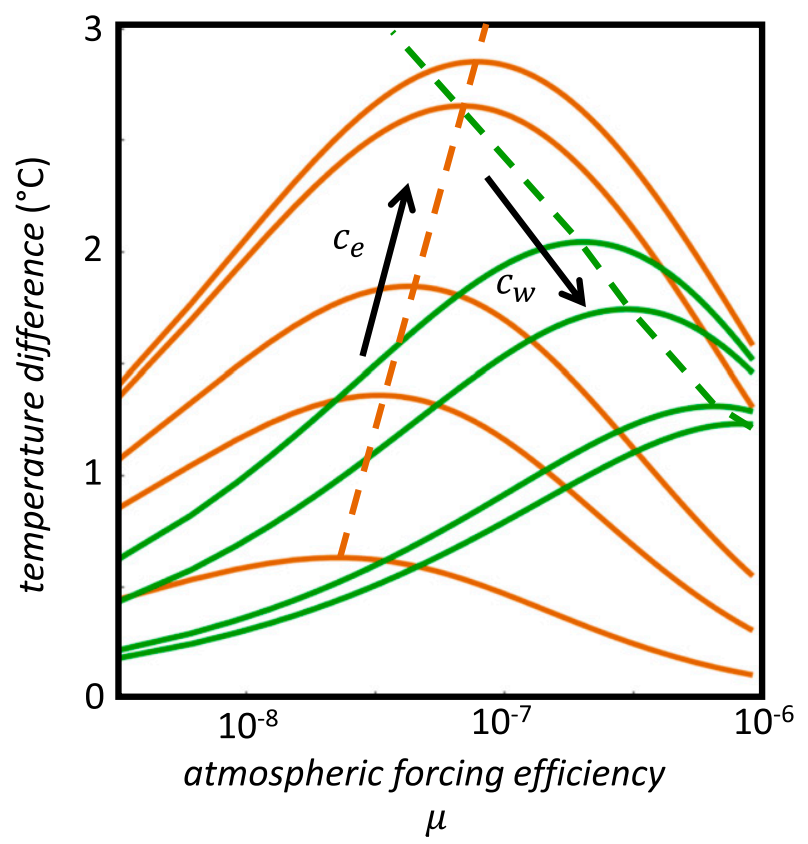

FIG. 9. Temperature difference between the eastern and western basins as a function of the nondimensional parameter $\mu$ (atmospheric forcing efficiency) for different values of the eddy efficiency parameters $c_{e}$ (orange curves) and $c_{w}$ (green curves). The dashed lines trace the maximum of the temperature difference curve, where the arrow indicates an increase in $c_{e}$ (keeping $c_{w}$ constant, orange dashed line) and an increase in $c_{w}$ (keeping $c_{e}$ constant, dashed green line). Note that the horizontal axis is logarithmic. (west) leads to a larger (smaller) temperature difference between the two basins. Figure 9, however, also shows that the maximum of the temperature difference is found for larger values of $\mu$ (stronger atmospheric forcing) when the eddy coefficients increase. Due to the complexity of Eq. (13), it is not possible to find an analytical solution for $\mu_{\max }$ and $\Delta T_{\max }$ that describes the dependence of the maximum of the temperature gradient between the eastern and western interior basins on the eddy coefficients $c_{e}$ and $c_{w}$. However, investigation of the maxima shows that for a linear increase in either $c_{e}$ or $c_{w}$ an exponential increase in $\mu_{\max }$ is needed to reach a maximum in the temperature gradient (not shown).

In summary, these results show that the 2basin_fullframework captures the dynamics of the idealized model simulations by providing good estimates for both the temperature of the different water masses in the marginal sea and for the transport estimates of the inflow, the front current and the slope current along the eastern boundary. Furthermore, analysis of the sensitivity of the marginal sea dynamics to changes in atmospheric forcing has shown that the two-basin approach leads to a nonlinear response of the temperature gradient between the eastern and western interior basins. As a consequence, changes in transport along the front current depend not only on the eddy efficiency near the eastern and western boundaries, but also on the strength of the atmospheric forcing.

\section{Discussion and conclusions}

In this study, we have proposed a dynamical system of a two-basin marginal sea subject to buoyancy loss that better addresses the complexity of the Nordic seas compared to previous one-basin studies described by, 
for example, Iovino et al. (2008) and Spall (2011). The conceptual model (the 2basin_full-framework) shows good agreement with idealized numerical simulations for a wide range in atmospheric forcing, implying that the physics of the conceptual model is relevant for a marginal sea like the Nordic seas (Figs. 7 and 8). To capture the hydrographic and dynamical differences of the Lofoten and the Greenland Basins, a two-basin geometry is essential. Additionally, we have shown that a simple extension of the one-basin conceptual framework described in Spall (2011) (the 2basin_simpleframework, section 3a) is not sufficient to capture the interactions between the two basins. Instead, to ensure a good comparison with the numerical two-basin marginal sea simulations, the inclusion of a front current and a downstream cooling of both the slope current and the front current is required (section $3 \mathrm{~b}$ and Figs. 7 and 8). Doing so, the 2basin_full-framework has elucidated the importance of the midocean ridge for separating two dynamically different regions and the essential role of the front current in governing the heat and volume budget of the Nordic seas.

The 2basin_full-framework provides estimates for the interior basin temperature of the Lofoten and Greenland Basins, the temperature of the outflow and the transport of the inflow, slope current and front current. The dynamics of the marginal sea are mainly controlled by the eddy fluxes from the slope current and front current and the strength of the atmospheric forcing, similar to Spall (2011). The extension from the 1basin-framework to the 2basin_simple-framework has shown that the sensitivity of the downstream (western) basin to changes in atmospheric forcing depends on the properties of the upstream (eastern) basin (Fig. 5). Due to the addition of the front current in the 2basin_fullframework, the upstream (eastern) basin is also sensitive to the properties of the downstream (western) basin, as the frontal strength and therefore the lateral eddy heat flux from the front depends on the temperature of both basins (Fig. 9).

The Lofoten Basin shows a weaker sensitivity to changes in the atmosphere than the Greenland Basin due to the enhanced eddy activity in the east (Fig. 4). As the Lofoten Basin and the Greenland Basin are connected via the slope current and front current, both the numerical two-basin simulations and the 2basin_fullframework show a nonuniform and nonlinear response to changes in atmospheric forcing. As a result, the temperature gradient between east and west can either increase or decrease when the atmospheric forcing weakens, depending on the strength of the atmospheric forcing before the weakening starts (Fig. 7a), and on the eddy coefficients of the eastern and western basins
(Fig. 9). In case of the present day Nordic seas, based on the reference simulation (indicated by the star in Figs. 7a and $8 \mathrm{c}$ ) and the conceptual model, one would expect a decrease in the density gradient across the midocean ridge and a weakening of the baroclinic component of the outer branch of the NwAC when the atmospheric forcing weakens.

The front current strength is of similar magnitude compared to the slope current in both the conceptual model and the numerical simulations. This is in agreement with recent observations of the front current from glider measurements (Bosse and Fer 2019). However, it is important to note that the characteristics of the slope and front current in the conceptual model are idealized in order to keep the number of free parameters at a minimum.

First of all, the derivation of the theoretical framework is based on only baroclinic currents. Observations have indicated that both the slope current and the front current have a substantial barotropic component (e.g., Orvik et al. 2001; Bosse and Fer 2019) and this could influence the derived heat budget in various ways. If the barotropic component would be included, the currents will likely be faster. As a result, the residence time in the mean flow is shorter and the subsequent temperature change due to direct heat loss to the atmosphere will be less. Furthermore, the barotropic component might induce other types of flow instabilities. It is however difficult to include a parameterization for those heat flux mechanisms in the conceptual model. Therefore, the sensitivity of the two-basin marginal sea to changes in the surface buoyancy forcing presented in this study should be interpreted as an upper limit, due to the omission of the barotropic component.

Second, in the 2basin_full-framework, the depth and width of the slope current and front current are chosen to be equal. The transect shown in Fig. $2 c$ indicates that the front current is much deeper than the slope current in this simulation. Regarding observations, a level of no motion is often not found, due to the strong barotropic character of the currents (e.g., Orvik et al. 2001; Bosse and Fer 2019). However, based on previous idealized model studies (e.g., Iovino et al. 2008) it is likely that the depth of the baroclinic component is related to the depth of the topographic sill (the Greenland-Scotland Ridge), which corroborates our choice for a constant depth. The width of the slope and front current is likely to vary in reality. Although we chose to constrain the depth, width, and baroclinic character of the slope and front currents in the conceptual model, the estimated temperatures compare well to the numerical simulations (Fig. 7), where these characteristics are clearly not set or constant. 
The conceptual model discussed in this paper represents a highly idealized representation of the Nordic seas, as the main aim of this study was to investigate the sensitivity of a two-basin marginal sea in comparison to the more common one-basin description. However, there are several components that could benefit from further investigation in order to better understand and predict the sensitivity of the Nordic seas to changes in atmospheric forcing. First, in the 2basin full-framework the only exchange between the eastern and western basins is via the slope current. Spall (2010) has shown that there is also a possible heat exchange between the interior of the Lofoten and Greenland basins as a result of the frontal current instability that impacts the stratification of the Lofoten Basin. Better understanding of what controls this exchange is needed to appropriately integrate this mechanism in our conceptual framework.

Furthermore, our conceptual model focuses on the role of temperature regarding atmospheric forcing and ocean dynamics. Salinity variations (or freshwater fluxes) can play an important role for, for example, the strength of the density gradient between the Lofoten and Greenland Basins, the dense water formation in the interior (e.g., Rossby et al. 2009; Brakstad et al. 2019), the atmospheric buoyancy forcing and slope current dynamics due to river runoff (Lambert et al. 2018). Spall (2012) has investigated the role of precipitation in a onebasin marginal sea and shows that abrupt transitions are possible due to a shutdown of convection. Furthermore, in both the theoretical framework and the idealized model simulations a linear equation of state is used with a constant thermal expansion coefficient, which is not necessarily appropriate for the Nordic seas where temperature differences are large (e.g., Mork and Skagseth 2005). Also the wind-driven dynamics of the real system are likely to play an important role for the variability of the processes discussed in this paper. All these processes might be important, but the main focus of this paper was to design a conceptual model to outline the importance of the two-basin character of the Nordic seas. Extending the two-basin conceptual framework to include some of these processes could enhance its predictive value.

In summary, this study has shown that a one-basin approach is not suitable to investigate the response of a marginal sea like the Nordic seas to changes in atmospheric buoyancy forcing. Instead, the results from the two-basin conceptual framework indicate that the dynamics of the eastern basin are linked to the dynamics in the western basin and that the response of the two basins combined is nonlinear. Therefore, for full understanding of observed changes in either the Lofoten or the
Greenland Basin, both basins need to be considered. Furthermore, the conceptual model developed in our study shows that the presence of the ridge and the front current amplify the sensitivity of the Nordic seas to changes in atmospheric buoyancy forcing (Fig. 6), both by increasing the net heat loss to the atmosphere (Fig. 7c) and by controlling the transport through the Nordic seas (Fig. 8). Further studies and observations of the front current dynamics are therefore important to better understand its role for the formation and export of dense water masses from the Nordic seas.

Acknowledgments. We thank Ilker Fer and two anonymous reviewers whose comments improved this paper. S. L. Ypma and S. Georgiou were supported by NWO (Netherlands Organisation for Scientific Research) VIDI Grant 864.13.011 awarded to C. A. Katsman. M. A. Spall was supported by National Science Foundation Grants OCE-1558742 and OPP-1822334. E. Lambert is funded by the ERA4CS project INSeaPTION. The model data analyzed in this study are available on request from the corresponding author. This study has been conducted using E.U. Copernicus Marine Service Information. The altimeter products were produced by Ssalto/Duacs and distributed by Aviso+, with support from CNES (https:// www.aviso.altimetry.fr).

\section{REFERENCES}

Andersen, C., N. Koc, A. Jennings, and J. Andrews, 2004: Nonuniform response of the major surface currents in the Nordic Seas to insolation forcing: Implications for the Holocene climate variability. Paleoceanography, 19, PA2003, https:// doi.org/10.1029/2002PA000873.

Blindheim, J., and S. Østerhus, 2005: The Nordic Seas, main oceanographic features. The Nordic Seas: An Integrated Perspective, Geophy. Monogr., Vol. 158, Amer. Geophys. Union, 11-37.

Blumsack, S. L., and P. Gierasch, 1972: Mars: The effects of topography on baroclinic instability. J. Atmos. Sci., 29, 10811089, https://doi.org/10.1175/1520-0469(1972)029<1081: MTEOTO $>2.0 . \mathrm{CO} ; 2$.

Bosse, A., and I. Fer, 2019: Mean structure and seasonality of the Norwegian Atlantic Front Current along the Mohn Ridge from repeated glider transects. Geophys. Res. Lett., 46, 13 170-13 179, https://doi.org/10.1029/2019GL084723.

Bracco, A., J. Pedlosky, and R. S. Pickart, 2008: Eddy formation near the west coast of Greenland. J. Phys. Oceanogr., 38 , 1992-2002, https://doi.org/10.1175/2008JPO3669.1.

Brakstad, A., K. Våge, L. Håvik, and G. Moore, 2019: Water mass transformation in the greenland sea during the period 19862016. J. Phys. Oceanogr., 49, 121-140, https://doi.org/10.1175/ JPO-D-17-0273.1.

Broomé, S., L. Chafik, and J. Nilsson, 2019: Mechanisms of the time-varying sea surface height and heat content trends in the eastern Nordic Seas. Ocean Sci. Discuss., https://doi.org/ 10.5194/os-2019-109.

Danabasoglu, G., and Coauthors, 2014: North Atlantic simulations in Coordinated Ocean-Ice Reference Experiments phase II 
(CORE-II). Part I: Mean states. Ocean Modell., 73, 76-107, https://doi.org/10.1016/j.ocemod.2013.10.005.

Dickson, R. R., and J. Brown, 1994: The production of North Atlantic Deep Water: Sources, rates, and pathways. J. Geophys. Res., 99, 12 319-12 341, https://doi.org/10.1029/94JC00530.

Eldevik, T., F. Straneo, A. B. Sando, and T. Furevik, 2005: Pathways and export of Greenland Sea water. The Nordic Seas: An Integrated Perspective, Geophys. Monogr., Vol. 158, Amer. Geophys. Union, 89-103.

Fronval, T., and E. Jansen, 1996: Rapid changes in ocean circulation and heat flux in the Nordic seas during the last interglacial period. Nature, $\mathbf{3 8 3}, 806-810$, https://doi.org/10.1038/ $383806 \mathrm{a} 0$.

Furevik, T., and J. E. Ø. Nilsen, 2005: Large-scale atmospheric circulation variability and its impacts on the Nordic Seas ocean climate-a review. The Nordic Seas: An Integrated Perspective, Geophy. Monogr., Vol. 158, Amer. Geophys. Union, 105-136.

Hansen, B., and S. Østerhus, 2000: North Atlantic-Nordic Seas exchanges. Prog. Oceanogr., 45, 109-208, https://doi.org/10.1016/ S0079-6611(99)00052-X.

Hurrell, J. W., Y. Kushnir, and M. Visbeck, 2001: The North Atlantic oscillation. Science, 291, 603-605, https://doi.org/ 10.1126/science.1058761.

Iovino, D., F. Straneo, and M. A. Spall, 2008: On the effect of a sill on dense water formation in a marginal sea. J. Mar. Res., 66, 325-345, https://doi.org/10.1357/002224008786176016.

IPCC, 2013: Climate Change 2013: The Physical Science Basis. Cambridge University Press, 1535 pp., https://doi.org/10.1017/ CBO9781107415324.

Isachsen, P. E., 2015: Baroclinic instability and the mesoscale eddy field around the Lofoten Basin. J. Geophys. Res. Oceans, 120, 2884-2903, https://doi.org/10.1002/2014JC010448.

_ C. Mauritzen, and H. Svendsen, 2007: Dense water formation in the Nordic Seas diagnosed from sea surface buoyancy fluxes. Deep-Sea Res. I, 54, 22-41, https://doi.org/10.1016/ j.dsr.2006.09.008.

_ I. Koszalka, and J. LaCasce, 2012: Observed and modeled surface eddy heat fluxes in the eastern Nordic Seas. J. Geophys. Res., 117, C08020, https://doi.org/10.1029/2012JC007935.

Lambert, E., T. Eldevik, and M. A. Spall, 2018: On the dynamics and water mass transformation of a boundary current connecting alpha and beta oceans. J. Phys. Oceanogr., 48, 24572475, https://doi.org/10.1175/JPO-D-17-0186.1.

Langehaug, H., D. Matei, T. Eldevik, K. Lohmann, and Y. Gao, 2017: On model differences and skill in predicting sea surface temperature in the Nordic and Barents Seas. Climate Dyn., $\mathbf{4 8}$, 913-933, https://doi.org/10.1007/s00382-016-3118-3.

Latarius, K., and D. Quadfasel, 2016: Water mass transformation in the deep basins of the Nordic Seas: Analyses of heat and freshwater budgets. Deep-Sea Res. I, 114, 23-42, https:// doi.org/10.1016/j.dsr.2016.04.012.

Marshall, J., A. Adcroft, C. Hill, L. Perelman, and C. Heisey, 1997: A finite-volume, incompressible Navier Stokes model for studies of the ocean on parallel computers. J. Geophys. Res., 102, 5753-5766, https://doi.org/10.1029/96JC02775.

Messias, M.-J., and Coauthors, 2008: The Greenland Sea tracer experiment 1996-2002: Horizontal mixing and transport of Greenland Sea intermediate water. Prog. Oceanogr., 78, 85105, https://doi.org/10.1016/j.pocean.2007.06.005.

Mork, K. A., and J. Blindheim, 2000: Variations in the Atlantic inflow to the Nordic Seas, 1955-1996. Deep-Sea Res. I, 47, 1035-1057, https://doi.org/10.1016/S0967-0637(99)00091-6.
— , and O. Skagseth, 2005: Annual sea surface height variability in the Nordic Seas. The Nordic Seas: An Integrated Perspective, Geophys. Monogr., Vol. 158, Amer. Geophys. Union, 51-64.

$\longrightarrow$, and $\varnothing$. Skagseth, 2010: A quantitative description of the Norwegian Atlantic Current by combining altimetry and hydrography. Ocean Sci., 6, 901-911, https://doi.org/10.5194/os6-901-2010.

Nilsen, J. E. Ø., and E. Falck, 2006: Variations of mixed layer properties in the Norwegian Sea for the period 1948-1999. Prog. Oceanogr., 70, 58-90, https://doi.org/10.1016/j.pocean.2006.03.014.

Orvik, K. A., and $\varnothing$. Skagseth, 2005: Heat flux variations in the eastern Norwegian Atlantic Current toward the Arctic from moored instruments, 1995-2005. Geophys. Res. Lett., 32, L14610, https://doi.org/10.1029/2005GL023487.

- _ _ , and M. Mork, 2001: Atlantic inflow to the Nordic Seas: Current structure and volume fluxes from moored current meters, VM-ADCP and SeaSoar-CTD observations, 19951999. Deep-Sea Res. I, 48, 937-957, https://doi.org/10.1016/ S0967-0637(00)00038-8.

Piechura, J., and W. Walczowski, 1995: The Arctic Front: Structure and dynamics. Oceanologia, 37, 47-73.

Poulain, P.-M., A. Warn-Varnas, and P. Niiler, 1996: Near-surface circulation of the Nordic Seas as measured by Lagrangian drifters. J. Geophys. Res., 101, 18237-18258, https://doi.org/ 10.1029/96JC00506.

Raj, R. P., S. Chatterjee, L. Bertino, A. Turiel, and M. Portabella, 2019: The Arctic Front and its variability in the Norwegian Sea. Ocean Sci., 15, 1729-1744, https://doi.org/10.5194/os-151729-2019.

Rhines, P., S. Häkkinen, and S. A. Josey, 2008: Is oceanic heat transport significant in the climate system? Arctic-Subarctic Ocean Fluxes, Springer, 87-109.

Richards, C. G., and F. Straneo, 2015: Observations of water mass transformation and eddies in the Lofoten Basin of the Nordic Seas. J. Phys. Oceanogr., 45, 1735-1756, https://doi.org/10.1175/ JPO-D-14-0238.1.

Rossby, T., V. Ozhigin, V. Ivshin, and S. Bacon, 2009: An isopycnal view of the Nordic Seas hydrography with focus on properties of the Lofoten Basin. Deep-Sea Res. I, 56, 1955-1971, https:// doi.org/10.1016/j.dsr.2009.07.005.

Sand $\varnothing$, A. B., and T. Furevik, 2008: Relation between the wind stress curl in the North Atlantic and the Atlantic inflow to the Nordic Seas. J. Geophys. Res., 113, C06028, https://doi.org/ 10.1029/2007JC004236.

Screen, J. A., and I. Simmonds, 2010: The central role of diminishing sea ice in recent Arctic temperature amplification. Nature, 464, 1334-1337, https://doi.org/10.1038/nature09051.

Segtnan, O., T. Furevik, and A. Jenkins, 2011: Heat and freshwater budgets of the Nordic seas computed from atmospheric reanalysis and ocean observations. J. Geophys. Res., 116, C11003, https://doi.org/10.1029/2011JC006939.

Spall, M. A., 2004: Boundary currents and watermass transformation in marginal seas. J. Phys. Oceanogr., 34, 1197-1213, https:// doi.org/10.1175/1520-0485(2004)034<1197:BCAWTI >2.0.CO;2. 2010: Non-local topographic influences on deep convection: An idealized model for the Nordic Seas. Ocean Modell., 32, 72-85, https://doi.org/10.1016/j.ocemod.2009.10.009.

2011: On the role of eddies and surface forcing in the heat transport and overturning circulation in marginal seas. J. Climate, 24, 4844-4858, https://doi.org/10.1175/2011JCLI4130.1.

, 2012: Influences of precipitation on water mass transformation and deep convection. J. Phys. Oceanogr., 42, 1684-1700, https://doi.org/10.1175/JPO-D-11-0230.1. 
Straneo, F., 2006: On the connection between dense water formation, overturning, and poleward heat transport in a convective basin. J. Phys. Oceanogr., 36, 1822-1840, https://doi.org/ 10.1175/JPO2932.1.

Tréguier, A.-M., S. Theetten, E. P. Chassignet, T. Penduff, R. Smith, L. Talley, J. Beismann, and C. Böning, 2005: The North Atlantic subpolar gyre in four high-resolution models. J. Phys. Oceanogr., 35, 757-774, https://doi.org/10.1175/JPO2720.1.

Trodahl, M., and P. E. Isachsen, 2018: Topographic influence on baroclinic instability and the mesoscale eddy field in the northern North Atlantic Ocean and the Nordic Seas. J. Phys. Oceanogr., 48, 2593-2607, https://doi.org/10.1175/JPO-D-17-0220.1.

Våge, K., G. W. K. Moore, S. Jónsson, and H. Valdimarsson, 2015: Water mass transformation in the Iceland Sea.
Deep-Sea Res. I, 101, 98-109, https://doi.org/10.1016/ j.dsr.2015.04.001.

Voet, G., D. Quadfasel, K. A. Mork, and H. Søiland, 2010: The mid-depth circulation of the Nordic Seas derived from profiling float observations. Tellus, 62A, 516-529, https://doi.org/ 10.1111/j.1600-0870.2010.00444.x.

Volkov, D. L., T. V. Belonenko, and V. R. Foux, 2013: Puzzling over the dynamics of the Lofoten Basin-A sub-Arctic hot spot of ocean variability. Geophys. Res. Lett., 40, 738-743, https://doi.org/10.1002/grl.50126.

Walin, G., G. Broström, J. Nilsson, and O. Dahl, 2004: Baroclinic boundary currents with downstream decreasing buoyancy: A study of an idealized Nordic Seas system. J. Mar. Res., 62, 517-543, https://doi.org/10.1357/0022240041850048. 